NUREG/CR-6435

PNL-10934

\title{
An Analysis of the Impacts of \\ Economic Incentive Programs on \\ Commercial Nuclear Power Plant \\ Operations and Maintenance Costs
}

Manuscript Completed: January 1996

Date Published: February 1996

Prepared by

D. C. Kavanaugh, W. H. Monroe, PNL

R. S. Wood, NRC

Pacific Northwest Laboratory

Richland, WA 99352

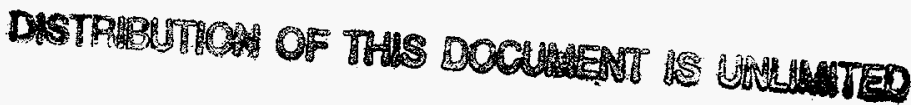

Prepared for

Division of Reactor Program Management

Office of Nuclear Reactor Regulation

U.S. Nuclear Regulatory Commission

Washington, DC 20555-0001

NRC Job Code L1236 


\section{DISCLAIMER}

Portions of this document may be illegible in electronic image products. Images are produced from the best available original document. 


\begin{abstract}
Operations and Maintenance (O\&M) expenditures by nuclear power plant owner/operators possess a very logical and vital link in considerations relating to plant safety and reliability. Since the determinants of O\&M outlays are considerable and varied, the potential linkages to plant safety, both directly and indirectly, can likewise be substantial. One significant issue before the U.S. Nuclear Regulatory Commission is the impact, if any, on O\&M spending from state programs that attempt to improve plant operating performance, and how and to what extent these programs may affect plant safety and pose public health risks. A prerequisite to understanding these linkages is to develop a framework to analyze the elements that affect the expenditures that are incurred in the post-construction, operating experience of plants. The rationale for analyzing the determinants of fixed O\&M outlays at plants is strengthened further by the recognition of the dramatic escalation of these costs during much of the operating lives of the reactor units. The cost performance of nuclear power plants in the United States was considerably worse than the industry and regulators anticipated during much of the 1970s and 1980s. Although the expenditure trends have seemingly slowed, continuing analysis is justified by the recognition of continuing regulatory changes and the re-structuring of the entire electric utility industry.
\end{abstract}

The purpose of this study is to examine the role and degree of impacts from state promulgated economic incentive programs (EIPs) on plant O\&M spending. A multivariate regression framework is specified, and the model is estimated on industry data over a five-year period, 1986-1990. Explanatory variables for the O\&M spending model include plant characteristics, regulatory effects, financial strength factors, replacement power costs, and the performance incentive programs. EIPs are found to have statistically significant effects on plant O\&M outlays, albeit small in relation to other factors. Moreover, the results indicate that the relatively financially weaker firms are more sensitive in their O\&M spending to the presence of such programs. Formulations for linking spending behavior and EIPs with plant safety performance remains for future analysis. 

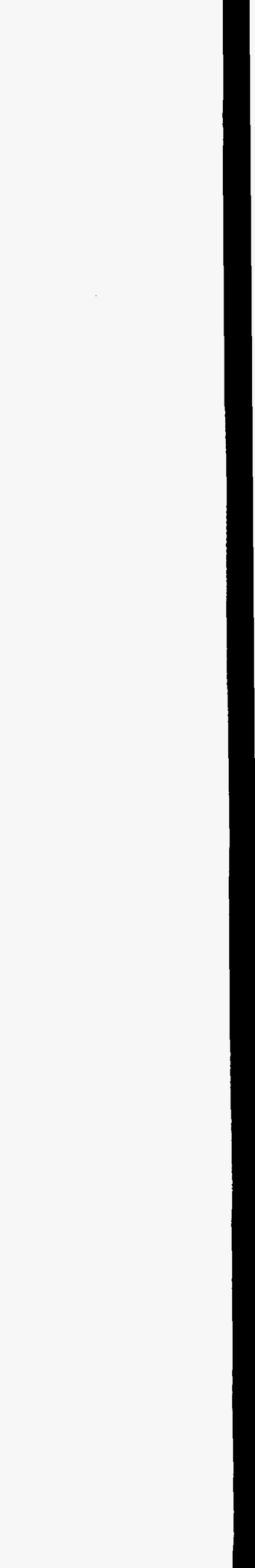

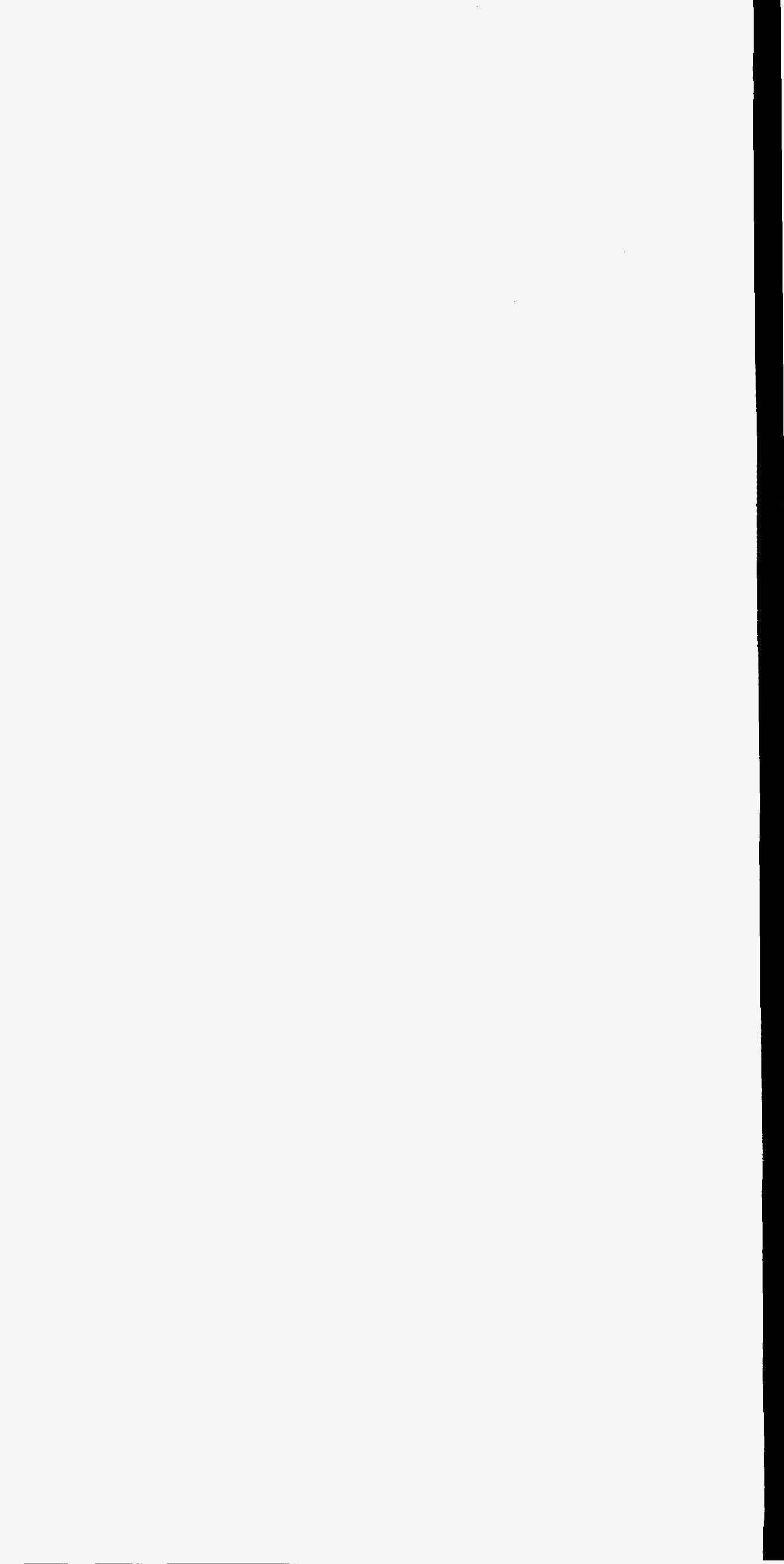
工

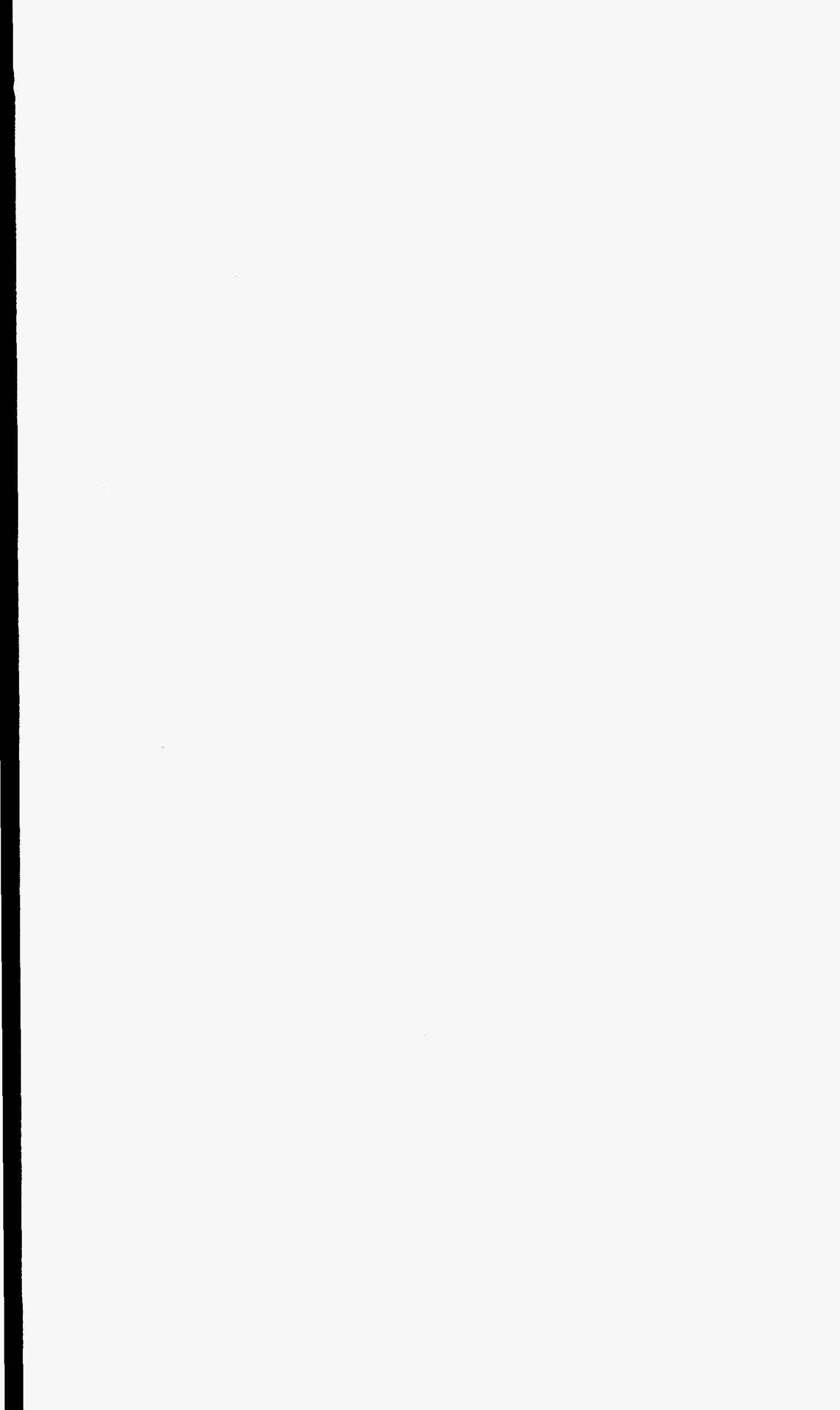




\section{Contents}

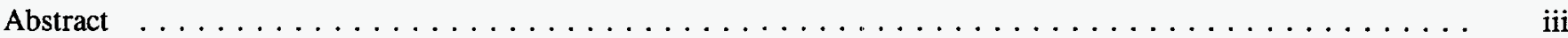

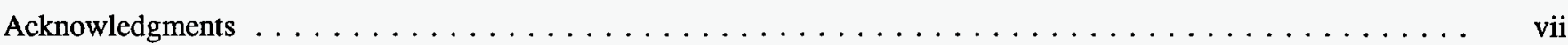

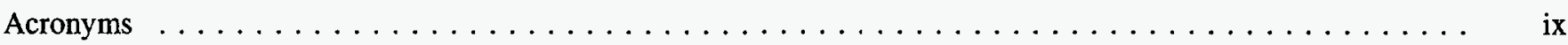

Summary $\ldots \ldots \ldots \ldots \ldots \ldots \ldots \ldots \ldots \ldots \ldots \ldots \ldots \ldots \ldots \ldots \ldots \ldots \ldots \ldots \ldots \ldots \ldots \ldots$

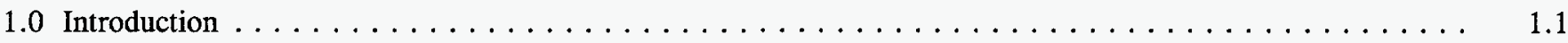

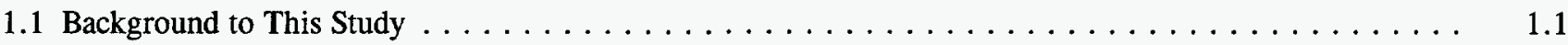

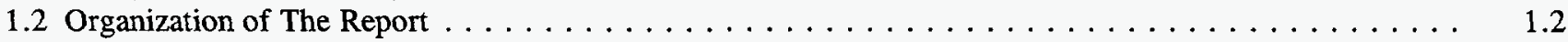

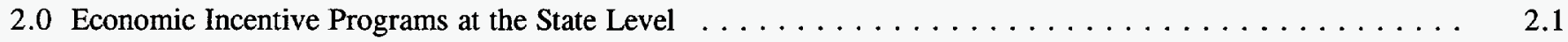

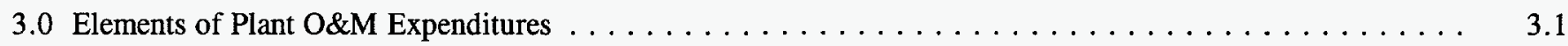

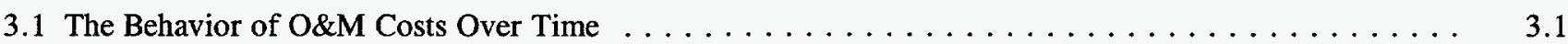

3.2 A Review of Other Studies on Plant Operating Performance $\ldots \ldots \ldots \ldots \ldots \ldots \ldots \ldots \ldots \ldots$

4.0 The Effects of EIPs and Utility Financial Status $\ldots \ldots \ldots \ldots \ldots \ldots \ldots \ldots \ldots \ldots \ldots \ldots \ldots \ldots \ldots$

5.0 The Econometric Model of Plant O\&M Expenditures $\ldots \ldots \ldots \ldots \ldots \ldots \ldots \ldots \ldots \ldots \ldots$

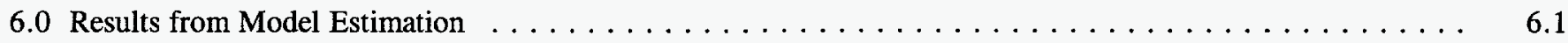

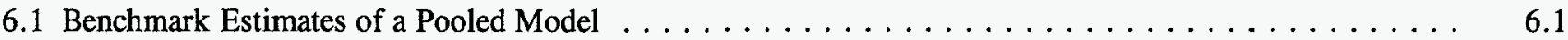

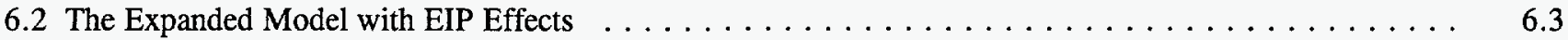

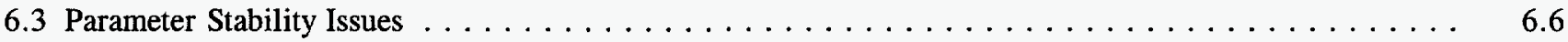

7.0 Inferences on EIPs and Financial Strength $\ldots \ldots \ldots \ldots \ldots \ldots \ldots \ldots \ldots \ldots \ldots \ldots \ldots \ldots \ldots$

8.0 Conclusions and Recommendations $\ldots \ldots \ldots \ldots \ldots \ldots \ldots \ldots \ldots \ldots \ldots \ldots \ldots \ldots \ldots \ldots$

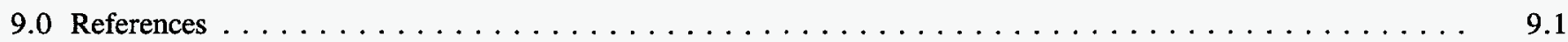

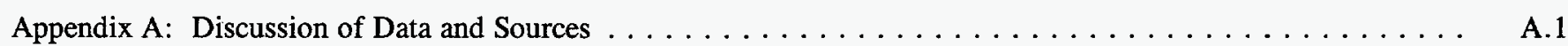

Appendix B: Measuring Utility Company Financial Status $\ldots \ldots \ldots \ldots \ldots \ldots \ldots \ldots \ldots \ldots \ldots \ldots$

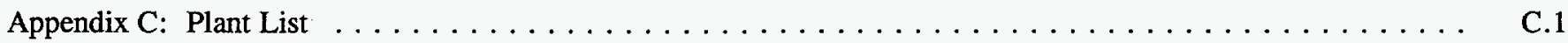




\section{Figures}

S.1 Real O\&M expenditures $\ldots \ldots \ldots \ldots \ldots \ldots \ldots \ldots \ldots \ldots \ldots \ldots \ldots \ldots \ldots \ldots \ldots \ldots \ldots \ldots \ldots \ldots$

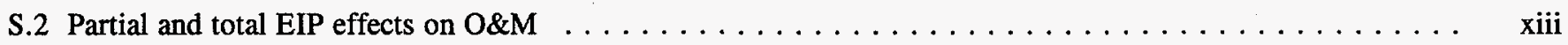

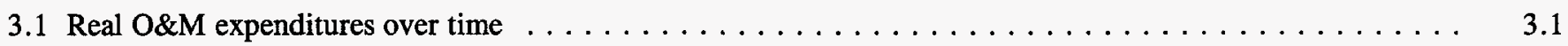

6.1 Purchase power costs and regulatory climate effects on $\mathrm{O \& M} \ldots \ldots \ldots \ldots \ldots \ldots \ldots \ldots$

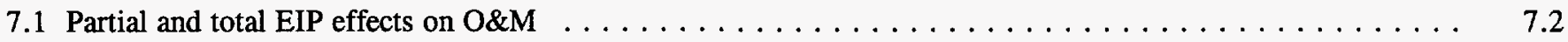

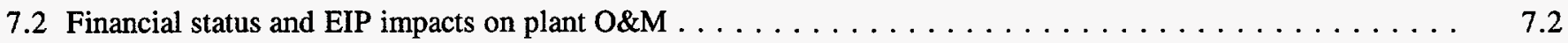

\section{Tables}

6.1 Regression results $\ldots \ldots \ldots \ldots \ldots \ldots \ldots \ldots \ldots \ldots \ldots \ldots \ldots \ldots \ldots \ldots \ldots \ldots \ldots \ldots \ldots \ldots \ldots .2$

6.2 Regression results of a yearly model $\ldots \ldots \ldots \ldots \ldots \ldots \ldots \ldots \ldots \ldots \ldots \ldots \ldots \ldots \ldots \ldots \ldots$ 


\section{Acknowledgments}

The Pacific Northwest National Laboratory staff researchers and the NRC staff would like to acknowledge the contributions of individuals, without implication for responsibility of our findings or conclusions. First, we appreciate the considerable time and helpful comments of Dr. Geoff Rothwell, of the Center for Economic Policy Research at Stanford University, as a discussant of an earlier presentation of some our modeling results. Mr. Gary Hovis of Argus Research provided the state regulatory ratings data. Mr. Robert Burns, Esq., of the National Regulatory Research Institute provided help in tracking fuel-cost adjustment mechanisms. G. Haber of Pacific Northwest National Laboratory supported the data base development. Dr. Kathryn Baker of Battelle Seattle Research Center and Dr. Ronald Schoenberg worked closely on methodological and data measurement aspects during the course of the research. Kevin Tyler also provided valuable comments to earlier draft versions of the report. 

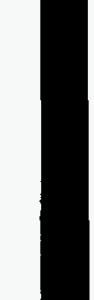


\section{Acronyms}

EIA Energy Information Administration

EIPs Economic Incentive Programs

FAC fuel adjustment clause

FERC Federal Energy Regulatory Commission

LSDV least squares dummy variable

MDA multiple discriminate analysis

MW megawatt

NARUC National Association of Regulatory Utility Commissioners

NRC U.S. Nuclear Regulatory Commission

NRRI Nuclear Regulatory Research Institute

O\&M operations and maintenance

OLSQ ordinary least squares

PRA probability risk assessment

PUC public utility commissions

RPPs replacement power expenses

TMI Three Mile Island

UDI Utility Data Institute 



\section{Summary}

This study presents an analysis of the determinants of non-fuel operations and maintenance expenses (O\&M) at commercial nuclear power plants for 1986-1990. O\&M expenditures by plant owner/operators possess a very logical and vital link in considerations relating to plant safety. Skimping on O\&M functions to meet a wide array of objectives or having expenditures subject to a variety of constraints poses potential questions about the resulting impact on public health and safety. Alternatively, overspending on a plant may unnecessarily drive up costs and ultimately increase rates to ratepayers. Since the determinants of O\&M outlays are likely to be many and varied, the potential linkages both directly and indirectly to plant safety can likewise be substantial. A logical pre-requisite to understanding these linkages is to develop a framework to analyze the elements that affect these expenditures that are incurred in the post-construction, operating experience of plants.

The rationale for analyzing the determinants of fixed O\&M outlays at plants is strengthened further by the recognition of the dramatic escalation of these costs during much of the operating lives of the reactor units. Figure S.1 underscores this rapid escalation during the 1970 s and 1980s. The chart shows O\&M costs normalized on a $\$ / \mathrm{kW}$ rate of net dependable capacity for the industry. During 1974-1984, real costs escalated at a rate of 12 percent, considerably in excess of general inflation and, even more significantly, in excess of design expectations. During the latter part of the period graphed in Figure S.1, however, these costs appear to have reached a plateau. They appear now to be growing at much lower rates of 3-4 percent, somewhat closer but still in excess of the general rate of inflation. Will this recent short experience develop into a longer trend, or will the elements underlying these expenditures change to bring about a return to the higher, more troublesome rates of the past? The analysis here examines plant O\&M from 1986-1990, a span of considerably more stable cost behavior.

While much of this cost behavior during the late 1970s and 1980s is attributable to new regulatory standards in the postThree Mile Island era, a number of other factors must be involved that have affected this temporal pattern. If there are a wide range of factors that affect these costs, then a unified representation of them would be indispensable in trying to

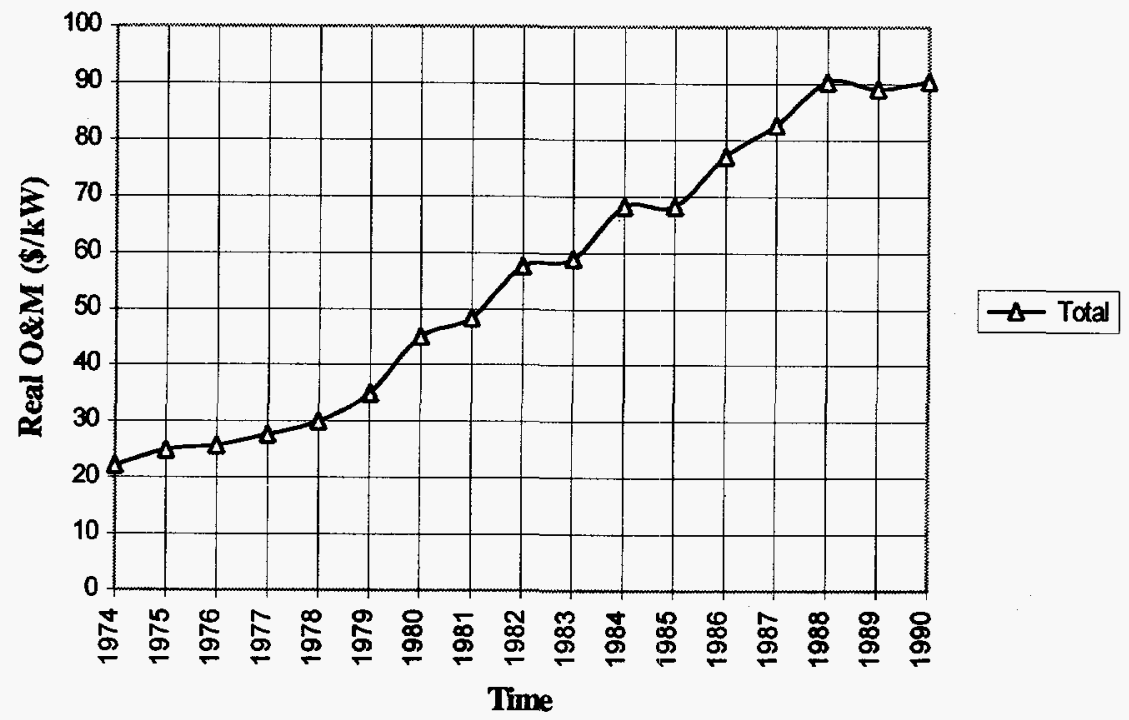

Figure S.1 Real O\&M expenditures (\$1990s) 
predict the future direction of O\&M expenses. Since any factor affecting O\&M costs may possess either direct or indirect casual influences over plant safety, understanding the factors in one, can conceivably carry over to the other.

Among this broad array of factors are the policies developed by state regulators directed at the utility level to promote efficiencies and to mitigate the need for rate increases to retail customers. Economic Incentive Programs (EIPs) have been largely promulgated by state regulators as a means of encouraging sustained or enhanced performance that would filter through to lower power costs to the utilities' retail customers. State-promulgated rules to promote operating and procurement performance of utilities may have important implications for policy concerns over the operating safety of nuclear power plants.

A collateral factor of importance for understanding and predicting the potential plant safety impacts stemming from O\&M functions is the role played by the overall financial vitality of the plant owner. Is there, for instance, a systematic relationship between financial strength and outlays supporting O\&M functions? Further, does the owner/operator's financial status affect the impacts, if any, from policies such as EIPs? This study makes a special effort at developing the necessary elements to embed this issue into the multivariate model.

Following other earlier empirical work on fixed O\&M costs, we segment the factors influencing O\&M costs into four primary categories: regulatory effects which stem from both federal and state oversights, physical effects such as plant age and size, financial effects, and, of course, EIP effects. The statistical framework employed is one of multivariate regression analysis. This technique permits isolation of the individual, casual factors underlying O\&M expenditures. Thus, while the general model incorporates all factors in the simultaneous determination of these costs, the regression approach allows us to concentrate on a given effect or factor while holding all others as fixed. Regression models can, however, be susceptible to specification errors and a potential for biases in the estimated effects can result from them. Considerable care, therefore, is required to guard against these pitfalls of a regression approach.

Our study draws upon a wide range of data sources in order to specify our model to span the four major categories of effects. The model is based on a time series of cross sectional data, meaning that we observe the O\&M behavior of a large number of different plants over a multi-year period, 1986-1990. Generally, the empirical results are quite strong in terms of the explanatory capability of the model's variables and for statistically significant factors. The findings on the two elements of concentration here are significant.

The estimates of the model indicate that EIPs are a significant factor statistically in explaining the observed behavior of plant O\&M expenditures over time. EIPs are generally found to have promoted higher spending levels on plant O\&M. However, an evaluation of the size of the effects indicates that they are comparatively small in relation to financial, regulatory and physical effects. Figure S.2 highlights the degree of impact that these programs have on plant O\&M outlays, over the five-year period 1986-1990. Because of their variety, EIPs are represented in the analysis by several broad characteristics for purposes of tractability. The first dimension is simply if such a program of any variety is present in the state jurisdiction in which the plant operates. The second distinguishing feature is if the program possesses specific reward/penalty structures for plant performance. These each represent "partial effects" and account for the first four columns in the figure, while the far right column in the figure accounts for the total or "composite" effect for our sample of plants on average.

Our results indicate that plants located in states with such EIPs generally spend about $\$ 2.3$ million per year more on O\&M than plants in states where EIPs have not be instituted. On average this amounts to roughly $\$ 0.5$ million for the 1986-1990 sample period; a comparatively small amount, but a positive and statistically significant one, nevertheless. 


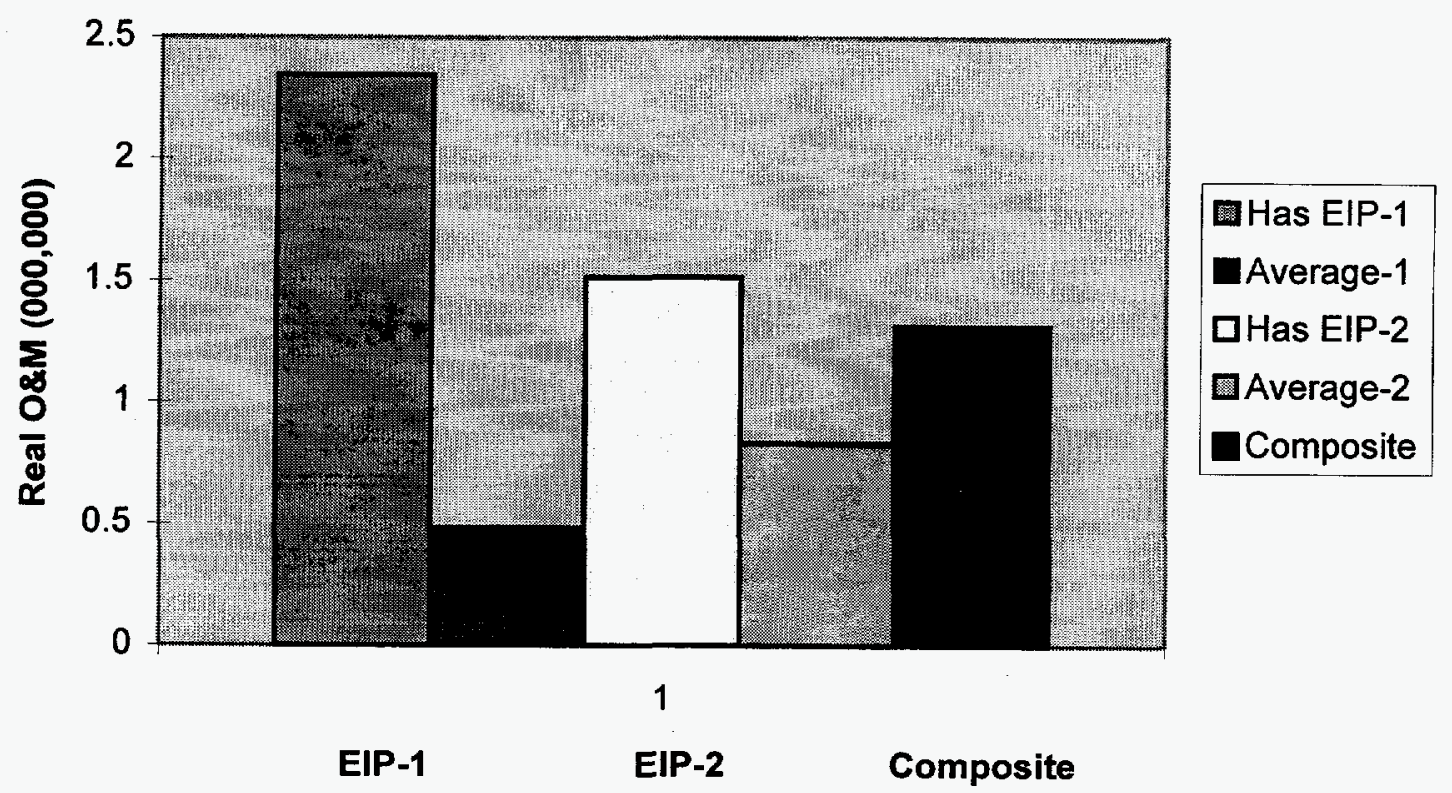

Figure S.2 Partial and total EIP effects on O\&M

EIPs which grant rewards or assess penalties for plant performance standards based on bands for the plant capacity factor are another, partial impact of EIPs contained in the model. Plants which operate under such incentive structures are estimated to spend approximately $\$ 1.5$ million more on O\&M annually than those plants that do not. Industry-wide, this partial effect accounts for roughly $\$ 0.83$ million per year more in O\&M outlays.

These partial effects are melded into a composite or total impact in the far right-hand side of Figure S.2. On average, EIPs appear to account for $\$ 1.32$ million per year more in plant O\&M spending. This is only slightly over 1 percent of average plant spending on non-fuel O\&M.

Our second major finding is that financial strength also appears to be a significant factor in plant owner/operator decisions relating to O\&M spending. This finding is very uniform across all the estimated models. Weaker financial firms are estimated to spend proportionately more on O\&M than do stronger firms in our sample, all else equal. This effect also carries over to owner/operator response to rewards/penalties under EIPs; weaker firms appear to respond to EIP incentive payments somewhat more than stronger ones do.

Other factors belonging to the regulatory and physical effects categories are found to be significant in a statistical sense, and in a dominate portion of the cases they are found to conform with the findings from other studies. 


\section{Introduction}

Much of the analysis of the problems besetting the nuclear commercial power industry has centered on the temporal behavior of non-fuel operations and maintenance costs. During the start-up years of commercial power generation spanning the 1970 s and 1980 s, non-fuel plant costs escalated at rates considerably in excess of industry and planning expectations, and also substantially in excess of general inflation. Moreover, other baseload generation technologies like coal-fired plants reflected much lower escalation rates, despite environmental control mandates. Coupled with these concerns, the industry has seen its role in the nation's energy future adversely affected by pressing issues such as the lack of a permanent repository for spent-fuel waste and by major structural changes buffeting the entire electric power sector. The latter span the trend toward increasing de-regulation, as recently represented by proposals to permit, or experiment with, the retail wheeling of power.

Within these broad issues, state regulators have increasingly developed policies directed at the plant level to promote efficiencies and to mitigate the need for rate increases to retail customers. Economic incentive programs (EIPs) have been largely promulgated by state regulators as a means of encouraging sustained or enhanced performance that would filter through to lower power costs to the utilities' retail customers. The substantial excess capacity that characterized the 1980s made EIPs even more compelling to regulators and customer groups. Statepromulgated rules to promote operating and procurement performance of utilities may have important implications for policy concerns over the operating safety of nuclear power plants. The linkages underlying these implications are exceedingly complex, involving influences of the behavior of utility managers, plant engineering, regulators at both the state and federal level, and the capital markets that play such a prominent part in this capital-intensive sector.

\subsection{Background}

Starting in 1989, the Pacific Northwest National Laboratory initiated reviews and surveys on state practices regarding EIPs for the U.S. Nuclear Regulatory
Commission (NRC) (Martin et al. [1989, 1991], McKinney and Elliot [1993], and very recently McKinney et al. [1995]). These surveys provided the logical building blocks with which to direct attention to analyzing or evaluating the impacts on plant operation and performance.

At the outset of this research, a concept study by Baker (1992) identified the direct and indirect linkages that could be of fundamental interest to regulators in the area of plant incentive structures:

(1) Is there a systematic effect of state-promulgated EIPs on plant safety performance?

(2) Do EIPs play a role in plant operations and maintenance $(\mathrm{O} \& \mathrm{M})$ expenditure decisions?

(3) Are EIPs a factor in the overall financial strength of plant owner/operators?

(4) Does financial strength affect the level of resources devoted by a plant owner/operator to fixed O\&M components?

(5) Are the levels of fixed O\&M expenditures at a plant and plant safety performance systematically linked to one another?

(6) Does financial status affect plant safety performance?

The empirical analysis here deals principally with items 2 and 4 . Items $1,3,5$, and 6 are examined in a multivariate analysis context by Baker et al. (1995).

The issues identified above obviously possess a considerable degree of complexity; they encompass engineering, economic and financial elements, management/ organizational behavior, and regulatory aspects. An integrated assessment of these complex systems and, in particular, their interactions would pose a rather daunting task. In this vein, there is a corollary question addressed in this research. Can highly aggregated statistical analysis of observations on the industry provide effective insight on the impact of regulatory and incentive programs on 
Introduction

plant performance and safety? Questions and issues of the variety posed here are amenable to two alternative approaches. The first can be referred to as a "system simulation" approach, which is intended to simulate the physical or engineering elements of plant operation. With the level of detail employed in this type of approach, the unit of observation is at the unit reactor level or on a casestudy basis. Each plant or unit has unique characteristics; so, a case-by-case analysis is typically the focus of analysis. For instance, the use of Probability Risk Assessment (PRA) approaches adopted by engineers is an example of this approach. PRA rests on developing decision trees (also known as event trees) which sequentially link the components of complex systems via branches. Risk is quantified by assigning subjective probabilities of failure to each branch emanating from the node of the tree and tracing each possible track through the system of nodes and branches that can lead to a serious event. Inherent in this approach is the belief that serious events are most probably the result of a sequence or compounding of failures rather than failure of a major component in isolation from other complex component systems.

The second, alternative approach is a statistical examination of the entire industry, based on econometrically estimated relationships for the group as a whole. The statistical framework employed is one of multivariate regression analysis. This technique permits isolation of the individual, causal factors underlying O\&M expenditures. Thus, while the general model incorporates all factors in the simultaneous determination of these costs, the regression approach allows us to concentrate on a given effect or factor while holding all others as fixed. Regression models can, however, be susceptible to specification errors and a potential for biases in the estimated effects can result from them. Considerable care, therefore, is required to guard against these pitfalls of a regression approach. However, this type of an approach, if found to be feasible, can complement case-by-case studies, and can be particularly beneficial for policy formation. Thus, part of the primary thrust of this study is to address the issue of the utility gained in studying the industry collectively and over time with statistical methods.

\subsection{Organization of the Report}

Section 2 of this report expands on the introductory comments in the context of the EIPs in particular. Section 3 presents issues relating to the fixed O\&M expenditures at nuclear power plants. The temporal behavior of these costs at plants has occupied a prominent place in analyzing the performance of nuclear generation technologies. A summary of empirical studies in this area is reviewed here. Section 4 serves to draw testable links between EIPs and owner/operator outlays at plants for non-fuel O\&M. Section 5 contains the empirical specification of the plant O\&M model, as well as a highlight of the data necessary to estimate the parameters of the cost function. Sections 6 and 7 report the results from estimation and the inferences regarding O\&M behavior at the plants in our sample. Section 8 presents conclusions from our analysis and the recommendations which emanate from them. The report is supplemented with several appendices.

Appendix A is a detailed discussion of the data and their sources. Appendix B is a brief summary of earlier work by the Pacific Northwest National Laboratory relating to measuring the financial strength of the electric utilities in our sample. Finally, a list of the plants underlying our sample information is given in Appendix C. 


\section{Economic Incentive Programs at the State Level}

When the influence of market-based or competitive forces is preempted by a high degree of regulation, as has traditionally been the case for electric utility companies during much of the century, concerns over resource efficiency losses become especially prominent. EIPs have been largely promulgated by state regulators as a means of encouraging sustained or enhanced performance that would filter through to lower power costs to the utilities' retail customers. Rate of return regulation and cost-ofservice regulatory principles effectively guided the industry during much of the post-WWII period. However, major structural changes occurring since the first oil embargo in the 1970s revealed the limitations from both a consumer and shareholder standpoint of the traditional regulatory practice. EIPs are probably best viewed as a component of regulatory reform, rather than a distinct regulatory element.
Incentive programs initiated by state regulatory agencies are used to help gauge a utility's efficiency in generation plant operation and to reward or penalize the owner/ operator for performance above or below established levels. The goals of EIPs are to promote sustained or improve performance and to achieve these with less regulation. Frequently, an EIP establishes a criteria for use in fuel cost adjustment proceedings to ascertain the allocations for cost recovery between ratepayers and utility shareholders. A number of approaches have evolved in the manner in which states adjust revenue requirements for cost recovery. In the context of EIPs strictly, a recent account is developed in McKinney et al. (1995), which builds upon earlier reviews and surveys (Martin et al. 1989, 1991; McKinney and Elliot 1993). 


\section{Elements of Plant O\&M Expenditures}

The temporal behavior of nonfuel, nuclear plant O\&M expenses during the 1970s and 1980s has attracted considerable attention by the industry, utilities and regulators alike. While this study seeks to examine a number of indirect relationships between plant performance and operator behavior in a regulated environment, a logical point of departure would be a review of other analyses that concentrate directly on plant O\&M expenditure patterns or other operational behavior. These existing studies serve the twofold purpose of identifying and assessing the factors that have affected plant expenditures in the past, as well as serving as useful benchmarks for evaluating the empirical analyses of our research. While a broad range of other studies are also reviewed, several serve the key purpose here of guiding and delimiting the scope of the empirical formulations examined.

\subsection{The Behavior of O\&M Costs Over Time}

The temporal pattern of O\&M costs over the dominant operating history of commercial nuclear steam-electric generation is reflected in Figure 3.1. The chart shows O\&M costs normalized on a $\$ / \mathrm{kW}$ rate of net dependable capacity for the industry. The rapid escalation which caught the attention of industry observers is captured during the 1970s and early to mid-1980s. During 19741984 , real costs escalated at a rate of 12 percent, considerably in excess of general inflation and, even more significantly, in excess of design expectations. During the latter part of the period graphed in the figure, however, these costs appear to have reached a plateau. They appear now to have grown at much lower rates of 3-4 percent, somewhat closer but still in excess of the general rate of inflation. The pattern has, however, tempered considerably in the last five years, in effect nearly leveling off in the last three years. Will this recent short experience develop into a longer trend, or will the elements underlying these expenditures change to bring about a return to the higher, more troublesome rates of the past?

\subsection{A Review of Other Studies on Plant Operating Performance}

Komanoff's (1981) work was one of the early studies to investigate the temporal behavior of nuclear power plant capital and O\&M costs. Using a sample of 46 plants placed into service during 1971-1978, Komanoff

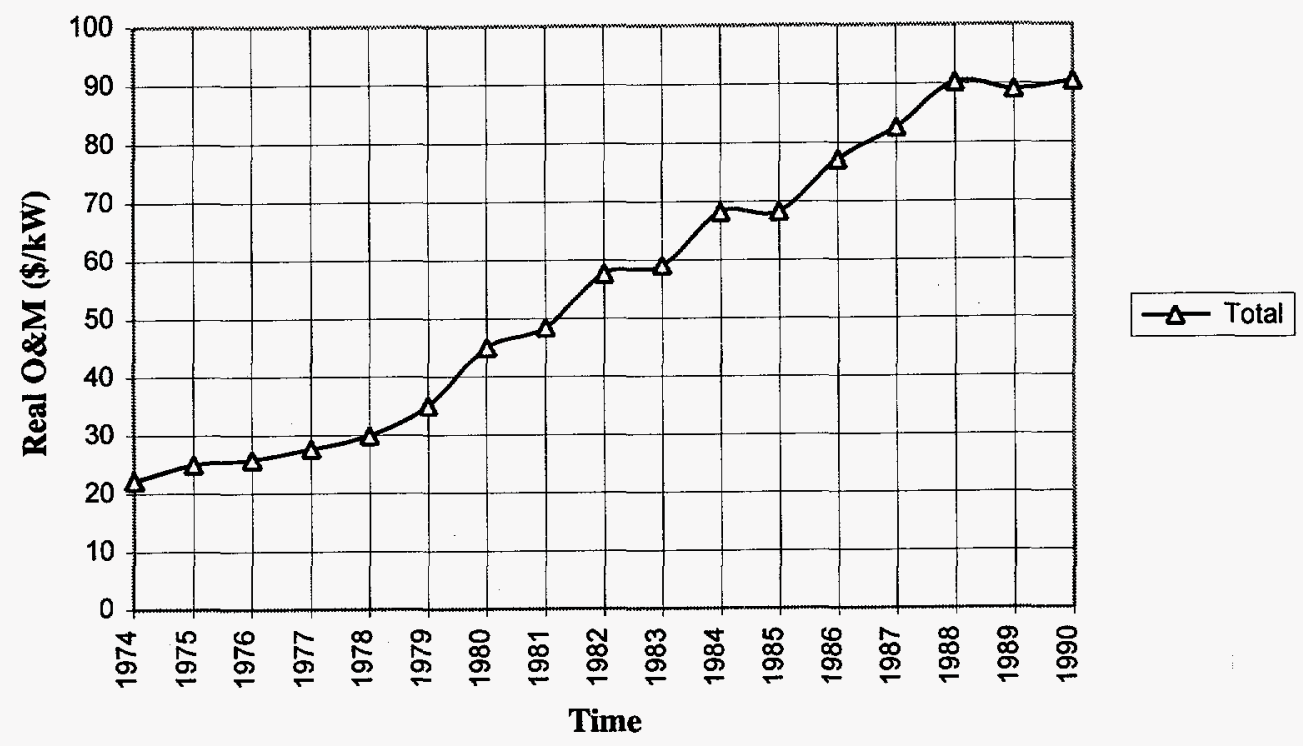

Figure 3.1 Real O\&M expenditures (\$1990s) 
determined that nuclear plant capital costs escalated in real terms at 13-14 percent per year, more than double the rate exhibited by coal-fired baseload capacity (which was largely beset with point-source pollution control requirements). Regulatory concerns over environmental impacts and plant safety issues were identified as the principal agents for the cost increases, and his outlook at the time of the study for the 1980s was for the trend to continue. Despite a somewhat simple statistical formulation, Komanoff's work nevertheless captured the cost trends plaguing the industry that were of considerable concern to regulators and utilities/industry alike.

A considerably more rigorous statistical model was formulated and estimated by the Energy Information Administration (EIA) at the U.S. Department of Energy (DOE) (EIA 1988). The EIA study took a more restrictive look at nuclear plant performance by examining nonfuel $O \& M$ expenses ("fixed O\&M" in industry parlance) and plant investment in post-startup years of a plant's operation. Like Komanoff, the EIA's study underscores the exceedingly high escalation of real outlays in these two cost components. Four major factors underlying this escalation are examined in a model based on the neoclassical model of factor demands in the production of electricity. First, the study specifies state regulatory practices regarding replacement power purchases and plant performance incentives as a factor. Coupled with these factors are other elements: plant age factors, NRC regulatory oversight activities, and relative factor costs.

Using annual observations from 1974-1984 on 51 plants, the study found that less permissive cost recovery for replacement purchases was associated with higher fixed O\&M outlays. O\&M costs showed an inverse relation to plant age; so, with all else equal, older plants revealed lower costs. NRC regulatory oversight, on the other hand, was associated with higher expenditure rates, as measured by fines or penalties levied for plant safety violations. Finally, there seemed to be some input substitution in the production function implicit in the models that reflected tradeoffs between variable inputs and capital inputs.

A follow-up study by the EIA (EIA 1991) was performed as an update to the earlier analysis. Carrying the factor demand approach further along the lines of the first study, this study examined the same elements with the aid of three years of additional observations. As well as serving as an updated examination, the study also sought to statistically test for structural change in the plant expenditure relationship. With regard to the latter issue, structural change from the earlier 1974-1984 period is rejected (but some interperiod effects were retained in some of the estimating equations), despite somewhat tempered escalation rates with the augmented data. With the updated sample observations on plants, state regulatory effects continued to exhibit positive impacts on O\&M outlays as jurisdictions are less permissive toward cost recovery of power purchases. Plant aging, all else held constant, continued to be associated with lower costs.

Thus, both study periods suggest that the learning effects seem to have dominated aging effects associated with physical deterioration, as developed and estimated in an earlier study by Joskow and Rozanski (1979). The expanded data set also continued to reflect a positive impact from NRC regulatory influences (that is, penalties for safety infractions), but they have diminished somewhat with time. The effects from substitution between variable factors and quasi-fixed inputs were found to be more muted than earlier, casting some doubt over any systematic input tradeoff.

Both EIA studies reflect some problems with variable measurement, as well as problems for the implications for the structure of production. Results from these studies are probably best interpreted as incomplete and serve as a useful point of departure for extending models along the lines of a production function based approach.

Another recent examination of the plant expenditure problem is a NRC staff study (NRC 1991). This study found some encouraging indications that cost escalation problems were brought under control in the post-Three Mile Island (TMI) period. Moreover, when put on a $\mathrm{kWh}-$ equivalent basis, the performance demonstrated improvement over the 1987-1990 period.

An alternative to using plant outlays to address these performance issues and causes is available through operating characteristics such as plant utilization rates. One such study, Rothwell (1990), examines plant capacity factors using a decomposition into a utilization-rate component and a service-hours component over the plant's refuel cycle. Spanning a period of observations with plant-level data from the late 1970 s to the early 1980 s, Rothwell's regression results for all reactors generally show that 
neither plant megawatt (MW)-size nor plant age have a consistent influence over these performance measures. While the results were considered mixed, the refuel cycle orientation of the data provides, nevertheless, an important insight into accurately gauging and judging reactor performance.

Krautmann and Solow (1992) is another study directed toward the plant performance and plant aging issue, with a particular emphasis on the post-TMI period. Using reactor data from 1968-1986, their study adopted the refuel cycle from Rothwell's study for the periodicity of operation and found that reactor performance during the period is independent of age overall, although once reactor technology type (pressurized water versus boiling water) is recognized, some performance-age relationships emerge. In the post-TMI era, these performance-age relationships pivot on reactor types. Boiling water reactors reflected a decline in performance, while pressurized water units reflected improvements in performance, but at a diminishing rate. Krautmann and Solow conclude that learning effects probably hold little chance for nuclear generation to gain a competitive place in the nations's energy resource stacks. 


\section{The Effects of EIPs and Utility Financial Status}

Within the broad context of our empirical analysis to investigate the significance of the six effects advanced in Section 1 , this section concentrates on a comparatively narrow subset of them. Specifically, to what extent, if any, do state-promulgated EIPs affect the level of O\&M expenditures at nuclear plants? Secondly, what is the direct, net impact on O\&M expenditure patterns due to the financial strength of the owner/operator of nuclear generation sites? With regard to the first issue, the ultimate matter is whether EIPs cause plants to be operated in such a fashion that they may pose the higher health and safety risks to the general public. The linkages can be, and are, numerous and varied, and some are probably more subtle and indirect than others. One relationship among the complex set of linkages is what, if any, relationship is there between such EIPs and owner/operator outlays for O\&M, which are themselves governed by a complicated set of factors? The goal of this research is not to test an $a$ priori hypothesis about the direction of such effects/ relationships. This would have to be based on considerably more detailed system analyses and possibly even these may produce indeterminate results in this regard. Rather, in our aggregated setting, we attempt to measure the direction for the EIP effects on O\&M composites and to see how significant these are statistically, all the while controlling for the broad spectrum of other factors that determine, or at least enter into, O\&M expenditure decisions.
Even in our somewhat highly aggregated framework, impacts of EIPs on O\&M can enter in a variety of ways and in some cases counteracting ones. Directly, we would expect the owner/operator to spend more on O\&M in the presence of EIP regulations to earn monetary rewards, decrease replacement power purchase costs, or to obviate penalties. The latter could have secondary effects which the owner may want to avoid by spending to increase performance. Counter to this incentive may be a situation where the owner directly (penalties) and indirectly (secondary effects) wants to avoid an adverse performance evaluation by taking short-cuts or deferring activities to bring a unit on-line to meet EIP standards, subject to at least meeting NRC safety standards and operating oversight. This could conceivably be heightened for those owner/operators who face a more highly constrained financial condition. The degree of state-regulatory stringency could also conceivably influence the O\&M deliberation under the presence of an EIP-type program, as well.

Just as for EIPs, the net outcome of how an owner/ operator's overall financial health may affect nuclear plant o\&M allocations, all else equal, is probably ambiguous as well from a reduced-form standpoint. It could either be the case that financially healthy firms spend more on plant O\&M as part of a well-managed, efficient system, or that such firms may have to relatively spend less because of management acumen and efficiency. ${ }^{1}$

\footnotetext{
${ }^{1}$ The very likely simultaneous link between a firm's financial health assessment by the capital markets and rating agencies and its management skill is dealt with in Section 5 in our treatment of measuring financial status of firms for the analysis.
} 


\section{The Econometric Model of Plant O\&M Expenditures}

For the initial specification to assess EIP and financial status effects, an additive model is advanced as: ${ }^{1}$

$$
\begin{aligned}
& O \& M_{i, t}=\alpha_{0}+\beta_{1} A_{G E} E_{i, t}+\beta_{2} O \& M_{i, t-j}+ \\
& B_{3} \text { AVEOUT }_{i, t-\mathrm{j}}+\beta_{4} \mathrm{RPP}_{\mathrm{i}, \mathrm{t}-\mathrm{j}}+ \\
& \delta_{1} \mathrm{RPP} * \mathrm{FAC}+\delta_{2} \mathrm{RPP} * \mathrm{FAC} * \mathrm{PUC}+ \\
& B_{5} \text { PENALTY }_{\mathrm{i},-\mathrm{j}}+\mathrm{B}_{6} \text { SIZEMW }_{\mathrm{i}}+ \\
& B_{7} \text { FSPRED }_{\mathrm{i}, \mathrm{t}}+\delta_{3} \text { PGTYPE} 1+^{-} \\
& \delta_{4} \text { PGTYPE2 }+\delta_{5} \text { PGTYPE } 3+ \\
& B_{8} \text { PGTYPE } 2 \$_{\mathrm{t} \cdot \mathrm{j}}+\Sigma_{\mathrm{k}} \delta_{\mathrm{k}+3} \text { YEAR }_{\mathrm{k}}+ \\
& \mathrm{e}_{\mathrm{i}, \mathrm{t}}
\end{aligned}
$$

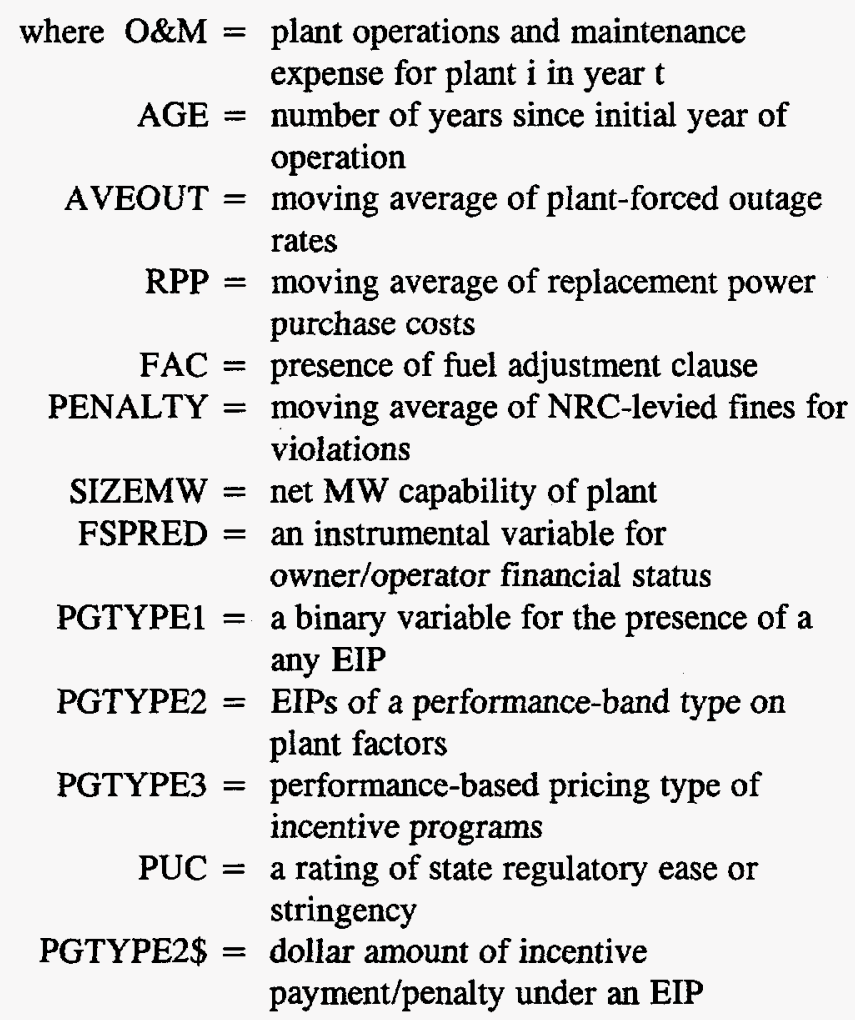

${ }^{1}$ In very preliminary analysis, both linear and $\log$-linear models were estimated. Some specifications were permitted to possess nonlinearities as well; see Section 6 below for further discussion. Many of the measured sensitivities appeared, however, to be largely invariant with respect to either form; so, for a majority of the regressions and for discussion of our results, the simple additive or linear model is used.

$$
\begin{aligned}
\text { YEAR } & =\text { binary variable for inter-year effects } \\
e_{i, t} & =\text { random disturbance term, iid } \sim \mathrm{N}\left(0, \sigma^{2}\right) .
\end{aligned}
$$

A discussion of each of the effects represented in the model follows. For this purpose and to highlight the statistical tests emphasized in this research, we have grouped these effects into the following segments: regulatory effects, EIP effects, financial effects, and physical effects.

Regulatory Effects: This class of effects includes the safety and operational oversight of the NRC. Since the Three Mile Island incident in 1979, NRC regulatory oversight and safety requirements increased considerably. These efforts, therefore, reflect the impact of regulation, as measured by fines or penalties levied on plants by the $\mathrm{NRC}$ for safety violations. The direct effect would largely be embodied in increases in O\&M outlays to remedy and to prevent future safety infractions. Indirectly, since NRC fines are a matter of public record and are frequently published in financial periodicals, an owner/operator may be sensitive to the potentially adverse impact such penalties may have on their capital costs.

This category also includes state fuel-cost adjustment mechanisms and state regulatory climate relating to cost recovery issues.

EIP Effects: This is the primary group of effects examined in this study and is somewhat more broadly specified in the model. Directly, a positive impact of EIPs would arise out of the owner/operator spending more on O\&M to remedy and obviate future plant performance problems. Indirectly, penalties under an EIP may have adverse impacts on the cost of capital not unlike those associated with the regulatory impacts discussed above. Three broad categories of EIPs are specified. First, a simple binary variable is specified for the presence of such a broadly defined program. The second is represented by specific programs based on performance bands and the calculation of rewards for exceeding the upper bound and penalties for failing to meet the lower bound placed around the plant's capacity factor. The third is comprised of programs characterized as performance-based pricing of the plant's output, and are also measured as a binary variable. 
Financial/Management Effects: These factors represent the direct impact of financial impacts from O\&M expenditures. They can reflect the cost-benefit tradeoffs in expenditure decisions. They can also embody indirect effects of outlays in reaction to higher cost of capital that result from comparatively low quality ratings of the utility at large. Since financial ratings are partly influenced by an assessment of the quality of management in making decisions consistent with the interests of equity investors, a low rating may reflect inefficient or excessive O\&M outlays, whereas more highly rated firms may do a better job at O\&M decision making and spend relatively less.

Physical Effects: Although not the prominent impacts for this analysis, these effects are nevertheless estimated with the model due to potential problems of specification error if they were omitted from the analysis. Effects of this type, to the extent they may be correlated with the error term, would result in biased coefficients if they were not included to as reasonable a degree as possible. Plant aging is an extremely important element for indications of future costs, it could logically warrant its own, separate analysis. However, that is beyond our scope here. No particular expectation is attached to this variable, we simply leave it to the data to reveal the qualitative direction of aging effects. Lagged unscheduled outage rates are used in the model as a predictor of future O\&M outlays. A plant's MW-size (which can be one reactor or several) is a scale effect that embodies the engineering design of reactor units and plant that balances capital, fuel, and maintenance costs. Economists have long been pre-occupied with optimal scale or size issues, particularly in the utility sector where regulation and resource allocation issues can be evaluated due to the wealth of good data. Studies on this matter have tended to concentrate on fossil-fuel fired steam electric generation; Kavanaugh and Ashton (1995) contains a survey of recent developments here.

Krautmann and Solow (1988) examines this matter for nuclear steam electric plants over the 1976-1978 period using flexible functional forms. Once care is taken to differentiate between single and dual reactor plants, they find that the former appear to be operating in the region of decreasing returns to scale while the latter are in the increasing returns to scale region of their respective longrun, unit-cost functions. The conclusion drawn is that single unit sites should be smaller plants, while dual reactor sites could be larger, the implication being that optimal size is dependent on the number of reactors at a plant.

Appendix A contains a detailed listing of the data and their sources that were developed for the estimation of models like Equation 5.1. Briefly, the list of data sources to support the construction of the estimation data base is comprised of

- Utility Data Institute, Power Plant Operations, 1981-1991

- Utility Data Institute, Company Data File, 1981-1991

- Utility Data Institute, Nuclear Power Plant File, 1981-1991

- Replacement Power Purchase Costs, 1984-1990

- National Regulatory Research Institute (NRRI) surveys on fuel adjustment cost mechanisms

- Moody's Bond Ratings for Electrics, 1982-1990

- Argus Research's PUC/PSC Ratings, 1985-1991

- Handy-Whitman industry cost data

- Selected gross domestic product deflators and other labor cost indexes.

The variable in Equation 5.1 labeled "FSPRED" measures the financial status of the utility owner/operator of the plants in our sample. Financial status is treated uniquely in the research and as a result merits some additional comment here. Appendix B contains a more complete discussion of developing financial status measures.

Because of the immense role played by the capital markets in the electric power industry (stemming mostly from rateof-return regulation and the capital intensiveness of electricity production), an attempt was made in the modeling to test for systematic influences reflective of the linkage of plant operating costs to financial markets. For instance, in the context of nuclear generation, Farber (1991) 
examined the association of the adoption of nuclear generation technologies in particular. His study looked at the long-term effects of the adoption of nuclear power plants on the cost of equity capital to U.S. electric utilities from 1956-1979. Farber estimated the impacts of the adoption of nuclear technology, the regulatory setting, and several company-level characteristics on the cost of equity to the firm as measured in the firm's beta coefficient. ${ }^{1}$ Farber's sample of 61 firms revealed that the adoption of nuclear steam-generation significantly increased the cost of equity (on average by 80 basis points) over the period, while controlling for a number of other sources of risk in the form of leverage, capital intensity of operations, and business diversity.
There is, therefore, a very probable degree of simultaneity between performance and the perceptions of the financial markets that requires recognition in our general expenditure model. We chose to adopt an instrumental variable approach to mitigate against this source of bias due to simultaneity. A model developed in Edelman (1991) was adopted and re-estimated on our data from the Utility Data Institute (UDI) data base and Moody's bond ratings.

Kavanaugh et al. (1993) contains a more complete discussion of the basis and results for variable creation, which is summarized in Appendix B of this report.

\footnotetext{
${ }^{1}$ The company's beta is one customary way of measuring systematic risk versus other common stocks, a result of relating a company's rate-ofreturn on common stocks to the market's rate-of-return.
} 


\section{Results from Model Estimation}

Our research strategy in this analysis is two-pronged. First, we use the O\&M models estimated by the EIA $(1988,1991)$ as a point of departure in specifying our model. The multivariate regression approach and the issues that are addressed in such studies are very similar to the objectives of this research. As a result, our initial statistical analysis concentrated on estimating "EIA-like" models for comparative purposes. Given the similarities, replications of the EIA models will serve to "benchmark" our results from the more extended model that is specified to measure EIP impacts. Secondly, our strategy offers an idea, albeit imperfectly, of how the prevalent results obtained in the EIA modeling carry over to more recent plant experience.

\subsection{Benchmark Estimates of a Pooled Model}

Table 6.1 contains a selection of the results from estimating models like Equation 5.1 over a time series of crosssectional observations on plants during the 1986-1990 period. Equation 1 in the table refers to the results obtained from estimating a model similar to the EIA models, data availability permitting. Equation 2 is essentially like the EIA specification with a broader representation of EIP elements included and is in the same "level-form" as the EIA equations. Equation 3 is a "least squares dummy variable" version of the model, specified to fix the timeinvariant factors that may differ across plants but which are not measurable with our sample information. It essentially relies on a separate binary variable for all plants but one in the estimation. Equation 4 is an alternative way of estimating the coefficients of the same, extended model of Equations 2 and 3, but in a form that is often labeled as "fixed effects." (The motivation for these representations is developed further in the equation-by-equation summary of our estimates.) Equation 5 in Table 6.1 refers to estimating the same model as contained in Equations 2 and 3, but using an analysis of the residuals to test for abnormally deviant error terms that may be the result of outliers in the data. All equations are estimated with an ordinary least squares (OLSQ) estimator.
Turning first to the replication of the "EIA-like" model, the degree of success can only be considered as mixed, but not having exactly similar data ostensibly precluded an "exact" replication of the results. Like the EIA model, ours explains only about 70 percent of the variation in plant O\&M expenses for the 1986-1990 period-not extremely high, but not uncommon for cross-section data. The overall precision of the model is not high either: the standard error of the model is $\$ 32.6$ million, slightly over 27 percent of the average expenditure level. Turning first to physical effects, our results do seem to correspond with those reported in both of the EIA studies $(1988,1991)$. Plant aging effects are negative, although in our sample they are not at the statistically significant level. So, while the inference drawn from the EIA analysis was that learning effects have dominated physical deterioration effects in so far as affecting plant O\&M outlays, we must accept neutral impacts in our replication. ${ }^{1}$ Like the earlier EIA studies, our sample also reflects a positive and significant effect on O\&M costs due to plant size and to the duration of unscheduled outages. ${ }^{2}$

Like both EIA analyses $(1988,1991)$ we find that owner/ operators respond directly to penalties levied by the NRC for safety violations ("PENALTY" in Equation 5.1). The cumulative impact of past penalty assessments has been the source of higher O\&M expenditures at plants. In the EIA model, state regulatory factors are multi-faceted: when firms have to purchase replacement power during unscheduled outages, regulators can exert a wide degree of influence over how these costs are recovered. The advent of fuel adjustment cost mechanisms stemming from

\footnotetext{
${ }^{1}$ This is probably overstating the strength of any inference from the data pertaining to the issue of plant aging effects. As noted above, the aspects of plant aging for such complex systems are hardly accounted for very well in a reduced-form expenditures model such as this. Thanks should go to Dr. Geoff Rothwell, a discussant of an earlier paper (Kavanaugh and Wood 1994), for driving home this point.

${ }^{2}$ The plant size-expenditure relationship is restricted in these models to be linear, which belies any indication about the optimal size in the dimension of fixed O\&M outlays. A number of simple alternative specifications were estimated on the models of Equation 2 through 4 in Table 6.1 that permitted nonlinearities to enter into the relationship. Although not unequivocal, there is some indication the sensitivity of outlays increases with plant size. Obviously, the optimal scale issue rests on considerably more than just this component of plant costs.
} 
Results from Model Estimation

Table 6.1 Regression results

\begin{tabular}{|c|c|c|c|c|c|}
\hline Variable & Equation 1 & $\begin{array}{c}\text { Equation } 2 \\
\text { LEVEL } \\
\text { FORM }\end{array}$ & $\begin{array}{l}\text { Equation } 3 \\
\text { LSDV on } \\
\text { PLANTS }\end{array}$ & $\begin{array}{c}\text { Equation } 4 \\
\text { FIXED } \\
\text { EFFECTS }\end{array}$ & $\begin{array}{c}\text { Equation } 5 \\
\text { STUDENTIZED }\end{array}$ \\
\hline Intercept & $23.5 *$ & $-20.2 * *$ & $114.1 *$ & - & - \\
\hline$O \& M(n, t-j)$ & $0.36 *$ & - & - & - & - \\
\hline \multicolumn{6}{|l|}{ Physical Effects: } \\
\hline AGE & -0.38 & -0.33 & $-2.8 * *$ & $-3.21 * *$ & -3.07 \\
\hline AVEOUT & $0.006 *$ & $0.005 *$ & $0.02 *$ & $0.019 *$ & 0.011 \\
\hline SIZEMW & $0.02 *$ & $0.05 *$ & $0.06 *$ & $0.07 *$ & 0.06 \\
\hline \multicolumn{6}{|l|}{ Regulatory Effects: } \\
\hline REP*FAC & -0.001 & 0.010 & $-0.37 *$ & $-0.035 *$ & -0.043 \\
\hline REP*FAC*PUC & 0.001 & $-0.003 * *$ & 0.004 & 0.003 & 0.004 \\
\hline PENALTY & $0.08 *$ & $0.15 *$ & -0.005 & -0.003 & -0.004 \\
\hline \multicolumn{6}{|l|}{ EIP Effects: } \\
\hline PGTYPE1 & - & $16.7 *$ & $45.0 *$ & $3.38 * *$ & 2.35 \\
\hline PGTYPE2 & - & -4.44 & - & - & - \\
\hline PGTYPE3 & - & 17.7 & $46.8 *$ & 0.61 & 3.35 \\
\hline PGTYPE2\$*FSPRED & - & $-3.19 * a$ & $-1.92 *$ & $-1.89 *$ & -2.03 \\
\hline \multicolumn{6}{|l|}{ Financial Effects: } \\
\hline RPP & $0.033 *$ & 0.015 & $0.04 * *$ & $0.040 * *$ & 0.05 \\
\hline FSPRED & - & $-24.7 *$ & $-14.8 * *$ & $-16.9 *$ & -14.6 \\
\hline Year & $* *$ & * & * & * & \\
\hline Estimator & OLSQ & OLSQ & OLSQ & OLSQ & OLSQ \\
\hline Obs & 178 & 213 & 213 & 214 & 203 \\
\hline Adj- $R^{2}$ & 0.68 & 0.78 & 0.89 & 0.55 & 0.67 \\
\hline R M S E & 32.59 & 28.3 & 20.0 & 17.9 & 12.7 \\
\hline Coeff $\cdot$ Var & 27.4 & 25.2 & 18.3 & 16.3 & 11.6 \\
\hline
\end{tabular}

* Statistically significant at the 95 percent level.

** Statistically significant at the 80 percent level.

a For this column only, the regressor is rewards/penalties assessed. 
the volatility of fuel markets in the mid-1970s is one prevalent regulatory vehicle. These proceedings provided an expedited means for utility cost recovery and prudence review outside the customary and very time-consuming arena of general rate cases, and thus served to ameliorate earnings attrition emanating out of regulatory lags. ${ }^{1}$

Directly, replacement power purchases (RPPs) are seen to be a positive element in O\&M costs, as found also in the EIA studies. This reflects the direct, financial selfinterest of the firm in spending more on O\&M to increase operating performance and, therefore, displace costly power purchases. When a utility has a FAC mechanism to resort to for cost recovery of fuel/purchases, there may be less of a tendency for this direct, financial effect to influence expenditure decisions. Unlike the EIA studies, we found no evidence in our benchmark regression for FACs being a factor in O\&M expenditures (when interacted with purchases). Moreover, this effect still appears nascent in our replication when we account for states that are considered difficult jurisdictions for such cost recoveries (as denoted by the variable public utility commissions [PUCs] interacted with purchases and the presence of FACs).

Finally, there are two other notable contrasts with the EIA formulations. First, the EIA models were all analyzed with O\&M costs measured in nominal, not inflation adjusted, dollars. This was mitigated to some extent by including "prices" on the right-hand side of the equation. Our sample seemed to permit estimation of the more conventional representation using real or constant dollar values directly. Second, the EIA models build dynamic effects into the model to account for lags and inertia. This typically has the effect of dramatically increasing the explanatory power of the model because of the lagged

\footnotetext{
The allocative effects of FACs have been the focus of number of studies that fall within the general analysis of electric utility production and cost functions. See, for instance, Gollop and Karlson (1978), Cowing and Stevenson (1982), and Atkinson and Halvorsen (1990). Generally, the prevailing findings from these are that FACs distort the resource decisions of utilities, in a fashion similar to that of rate-of-return regulation distorting capital and variable factor decisions. Averch and Johnson (1962) first advanced this thesis formally and it has been the source of considerable empirical research. Kavanaugh and Ashton (1995) contains a source of relevant citations in the general context of modeling utility production/cost functions under regulatory constraint.
}

endogenous variable. ${ }^{2}$ Another result of this is to attach a temporal feature to the estimated effects. The coefficients estimated directly are considered to be short-run coefficients, whereas the equilibrium form of the model suggests coefficients that "allow" adjustments to take place and, therefore, have a long-run interpretation. In our empirical analysis, there appeared to be little difference between the inferred long-run impacts of the explanatory variables from those in models estimated in equilibriumform already (that is, sans the lagged endogenous). As a consequence, in all of our results presented subsequently, only the equilibrium versions are presented. Nothing seems to be gained (except higher R-squares) by using the lagged moving average of the dependent variable and there is considerably more tenuousness in the quality of the estimator as a function of the stochastic assumptions governing the model. We chose to obviate the latter, since "maximizing" R-square was not an objective of this investigation.

\subsection{The Expanded Model with EIP Effects}

Equation 2 of Table 6.1 is the same model as Equation 1 with the broader array of variables to account for the influence of EIPs. In this absolute level form, we see that the implications for regulatory effects and physical effects are largely unchanged over the benchmark regression. In fact, there is a slight improvement in terms of statistically significant results. The dollar impact on O\&M from NRC penalties is found to be much lower, but still a statistically significant result. Two of the four EIP variables attain significance in this extended model. The sheer presence of a general EIP appears to be associated with nearly $\$ 17$ million more outlays for O\&M in our samples a somewhat surprising and dramatic impact. The direct impact of the dollar reward/penalty under this type of EIP (the variable PGTYPE2\$ in Equation 5.1) is positive on the level of O\&M. On average the incentive payments for performance under this type of program have been negative (that is, they have been penalties assessed on the plant's operator by the states); so, the impact has been to increase O\&M outlays. For every hundred-thousand

\footnotetext{
${ }^{2}$ The EIA specification is actually a moving average of lagged values; so, it is actually a slightly more awkward dynamic structure than, say, the more common-place geometrically distributed lag.
} 
dollars of penalties, there is an indication of a considerable multiplier effect on O\&M of roughly $\$ 3$ million.

The second major extension of the model over the EIA prototype of Column 1 in Table 6.1 is the examination of the effects of an owner/operator's financial status on O\&M expenditure patterns. Using the instrumental variables approach discussed above, we find a statistically strong and positive effect associated with the FSPRED regressor. Higher expenditures on O\&M are associated with financially weaker firms as measured by bond ratings.

On both counts, it does appear from these initial estimates that not specifying EIP effects and financial strength effects in a model of fixed O\&M expenditures would be a misspecification of the model. To the extent that variables exist which may share some correlation with EIP effects, biased coefficient estimates should be expected unless the EIP effects are represented explicitly.

Equation 4 in Table 6.1 is an identical set of estimates of the coefficients of the extended model, except it is specified and estimated as a fixed effects model. In models of combined or "pooled" cross sectional observations on micro-unit data such as for households or firms, there can be a number of effects that influence the variable under analysis, just like O\&M expenditure behavior at different plants. However, sample information is virtually always subject to resource constraints and, as a result, is far from ideal. Some variables may be omitted from our list of regressors as a consequence of this. To illustrate the fixed effects model as an approach to parameter estimation, let the following abridged representation of our plant O\&M cost equation be given as

$$
\mathrm{y}_{\mathrm{i}, \mathrm{t}}=\alpha_{\mathrm{i}}+\sum_{\mathrm{j}}^{\mathrm{k}} \beta_{\mathrm{i}, \mathrm{j}} \mathrm{x}_{\mathrm{i}, \mathrm{j}, \mathrm{t}}+\mathrm{e}_{\mathrm{i}, \mathrm{t}}
$$

where $y_{i, t}$ can represent O\&M outlays at the $i$-th plant in period $t$. The $x_{i, j, t}$ summarizes all the explanatory variables, $j=1$ through $\mathrm{k}$, for this $\mathrm{i}$-th plant in period $\mathrm{t}$. The $\mathrm{e}_{\mathrm{i}, \mathrm{t}}$ is the same as the stochastic disturbance term in Equation 5.1, and $\alpha_{\mathrm{i}}$ is the average influence on O\&M at plant $i$ resulting from all the non-random effects omitted in our list of $x_{j}$. In Equations 1 and 2 of Table 6.1, we've implicitly taken $\alpha_{\mathrm{i}}=\alpha_{0}$ and $\boldsymbol{B}_{\mathrm{i}, \mathrm{j}}=\boldsymbol{\beta}_{\mathrm{j}}$ (that is, the constant term and all the slope coefficients are treated as equal across the plants). These are statistically testable propositions and this is dealt with directly at a later point in this section.

The restriction on $\alpha_{0}$ can be readily relaxed by specifying a binary variable for each plant (less one which is subsumed within the intercept term) and permitting the intercept to effectively differ for all but one plant. This is done in the results under the heading "LSDV on PLANTS" in Table 6.1, and is commonly called a "least squares dummy variable" version of Equation 5.1. However, because $\alpha$ accounts for the average effects of omitted influences, it is imminently possible that one (or more) of these exist that do not depend on time but depend on the plant/firm. Since $\alpha_{i}$ represent the time-invariant effects of unobserved factors in O\&M expenditures, it is possible that "part" of $\alpha$ is not really fixed, but contains random components that conceivably could be correlated with the known or measured regressors in the model. Examples of factors such as this would be reactor type and the vendor or plant MW-size. These are fixed effects over time for each site (unless, for the latter, another reactor unit comes on line in our period of observation), but they do vary by plant. Had we not had observations on these time-invariant variables, these effects would reside in $\alpha_{0}$ or $\alpha_{i}$. To the extent correlation exists, biased coefficient or estimated impacts would result. ${ }^{1}$

As long as these omitted influences are only random across plants and invariant over time, the deviation-fromthe-mean form of Equation 6.1 provides a remedy, albeit somewhat drastic in light of the broader structure of errorcomponents models (where $\mathrm{Z}$ denotes the mean of a variable $\mathrm{z}$ ):

$\mathrm{y}_{\mathrm{i}, \mathrm{t}}-\mathrm{Y}_{\mathrm{i}}=\alpha_{\mathrm{i}}-\alpha_{\mathrm{i}}+\sum \beta_{\mathrm{j}}\left(\mathrm{x}_{\mathrm{i}, \mathrm{j}, \mathrm{t}}-\mathrm{X}_{\mathrm{i}, \mathrm{j}}\right)+\mathrm{e}_{\mathrm{i}, \mathrm{t}}-\mathrm{E}_{\mathrm{i}}$

or using a $\_$to denote a deviation from the mean:

$$
\Delta y_{i, t}=\sum \beta_{j} \Delta x_{i, j, t}+e_{i, t}
$$

\footnotetext{
'This situation actually characterizes only a special case of a more general model called the error (or variance) components model. Judge et al. (1980) contains a convenient summary of the taxonomy of such models and recommendations for econometric estimation.
} 
Thus, the fixed effects version of Equation 5.1 forces the random, omitted influences contained in $\alpha_{\mathrm{i}}$ to drop out upon forming deviations, and preserves unbiased estimation of the effects of EIPs, as well as other effects.

Equation 4 of Table 6.1 contains the results from estimating the O\&M expenditure model in this fixed effects formulation. In contrast to the level-form version represented in Equation 2, several important differences emerge. First, the fixed effects estimates of EIPs indicates that the presence of such incentive programs has a dramatically smaller impact on outlays than in the level version of the model. The dollar impact falls by nearly 80 percent (from $\$ 16.7$ million to $\$ 3.4$ million). Performance-based pricing programs, however, still do not attain statistical significance in the fixed effects version. The dollar impact of EIP incentive payments/ penalties also appears to decline somewhat in this version, although now it is a function of financial strength while in Equation 2 it is estimated as independent of strength. At average strength, the fixed effects model estimates do suggest that the level-form of the model tends to overstate the effect of EIP ( $\$ 3.2$ million versus $\$ 0.83$ million, or roughly by four times). In all, the fixed effects representation of the model appears to have a very strong influence on measuring the size and significance of EIPs on plant O\&M costs.

Another dramatic illustration of the potential bias that can surface in an ill-specified model is seen by comparing the estimated EIP effects in the least squares dummy variable (LSDV) version with those of the fixed effects version. In the former, both PGTYPE1 and PGTYPE3 (from Equation 5.1) programs are substantially positive and significant statistically, and the presence of either would account for roughly one-half of a year's outlays at a given plant! Vis-a-vis the fixed effects estimates, this is nearly a 15 times greater impact - an unreasonable and highly overstated effect that is remedied with the fixed effects estimator.

The other principal regulatory-effects variable in the model, the penalties levied by the NRC for plant safety violations, also changed dramatically under the fixed effects version. In contrast to being positive and statistically significant under the level-form version, it is now negative and not significant. Penalties, either directly or indirectly appear to not have an impact on plant outlays in this fixed effects representation. The dual financial and regulatory effects represented by RPP and state cost- recovery practices (FAC and PUC) are also seen to take on significantly different roles in this version. First, the direct economic impact of RPP costs become statistically significant at nearly the 90 percent level. Second, we now discern how this direct impact is partly mitigated by the presence of FACs. The negative and significant coefficient on RPP*FAC (from Equation 5.1) indicates that plant owner/operators spend less on O\&M as a function of RPP costs if cost recovery options are wider. Figure 6.1 illustrates this behavior. O\&M costs increase as RPP costs rise, but at a slower rate when FAC options are present. The degree of state regulatory ease or tightness further modifies the size of the impacts: more lenient jurisdictions on cost- recovery issues suggest that the O\&M impacts can be considerably less than when it is considered more stringent.

The other major issue of importance to this study is that of the role of a owner/operator's financial status and the level of expenditures at a plant. The financial effects variable, FSPRED in Equation 5.1, continues to have a strong and significant association with outlays. Financially stronger firms exhibit lower plant outlays, all else held constant.

In terms of physical effects, the results are generally comparable to the level-form approach. However, this version does produce considerably stronger, negative effects of plant aging. During our 5-year period of plant observations, the net results of learning effects appear to dominate physical deterioration effects. Not only is the effect nearly 10 times larger under this version, it is highly significant as well. Both of the other physical effects variables reveal increases in the estimated impacts; there is, for example, a 40 percent increase in the slope coefficient associated with plant MW-size.

In terms of the "quality" of the statistical relation, the percent of explained variation for this version appears lower at 53 percent, but this is in terms of deviations from the mean of the dependent variable. Using a level-form equivalent would provide an approximate coefficient of determination of over 80 percent; so, the explanatory power of the model is at least as high as Equations 2 and 3. As well, there is a noticeable drop in the root mean squared error. It is $\$ 17.9$ million here or 35 percent lower than in the level-form approach, a considerable decrease that indicates a major improvement in precision of the overall regression model. 
Results from Model Estimation

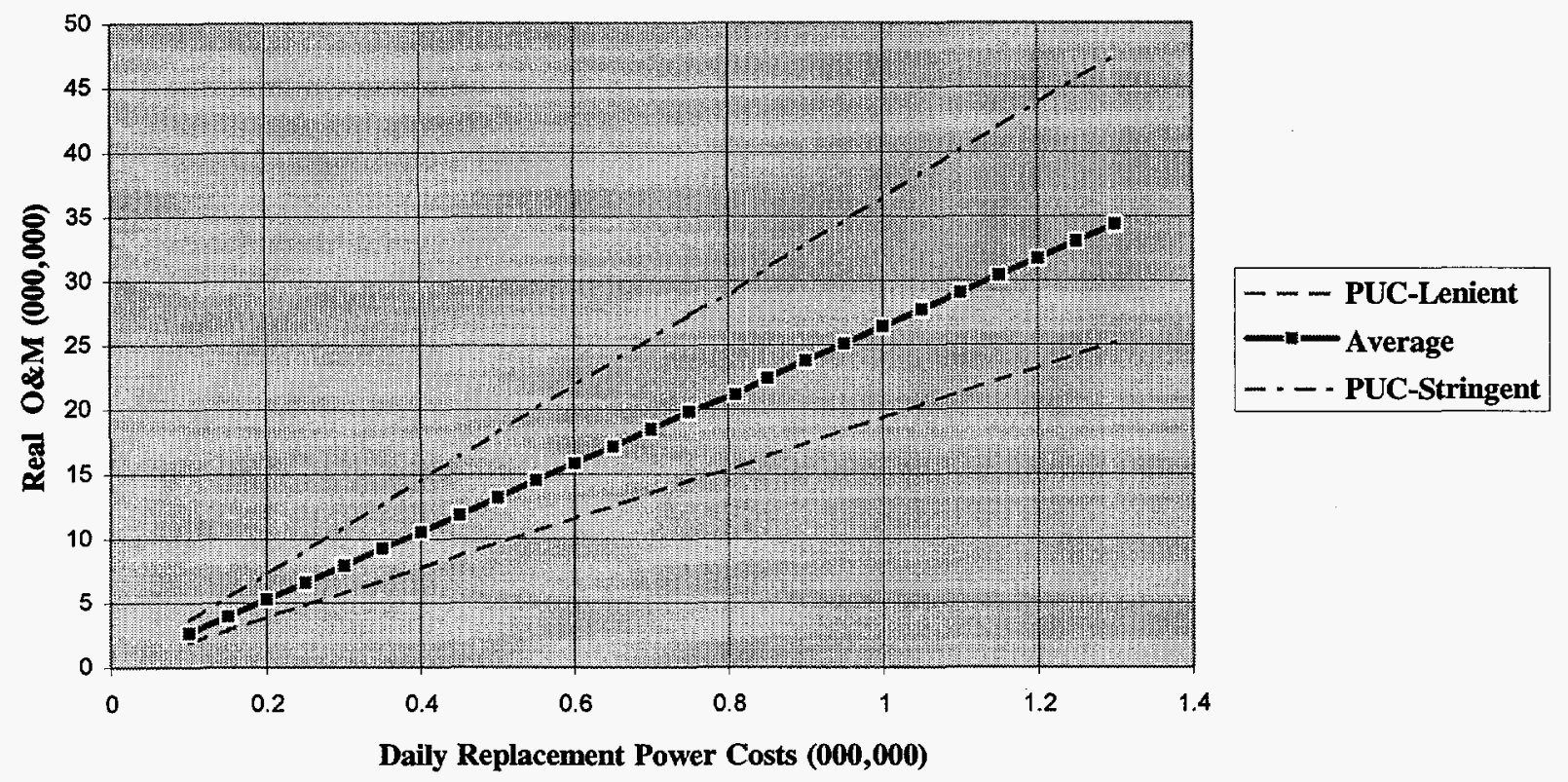

Figure 6.1 Purchase power costs and regulatory climate effects on O\&M

\subsection{Parameter Stability Issues}

Overall, our results in Table 6.1 appear to provide very encouraging results on the detection of EIP effects in the context of a general O\&M expenditure model. The replication of the EIA model for benchmarking purposes was also largely successful. The fixed effects version of Equation 5.1 provided dramatic differences over the initial, level-form of the model (Equation 4 versus Equation 2 of Table 6.1). EIP impact estimates are materially improved upon estimation of the fixed effects model. The fixed effects representation also proved to generate more credible results over the LSDV representation for plantspecific effects, while maintaining nearly identical results for financial, physical, and NRC-related effects.

All equations in Table 6.1 are estimated as pooled time series of cross section data under the implicit assumption that the slope coefficients are the same for all years. Under this hypothesis, greater precision on the estimated parameters would apply. This is a statistically testable proposition, and is a check of whether such pooling and its benefits are acceptable in lieu of estimating the model for each year separately. The test is based on an F-statistic for the restriction of identical slopes for all years versus the unrestricted estimation of different slopes for each year. ${ }^{1}$ The F-statistic is determined to be 4.20 with 22 and 192 degrees of freedom. The tabled value for an F-distributed random variable with 20 and 200 degrees of freedom is 1.97 at the 1 percent error level. The null of equal slopes is therefore rejected by our sample data at a very high level of significance, and yearly regression are indicated.

As part of the research diagnostics, Table 6.2 gives the results of the yearly regression results for the fixed effects representation. The results indicate considerable instability or inter-year differences in the sets of slope coefficients. Table 6.2 reveals major differences with respect to EIP effects, only 8 of the total number of 15 parameters conform in sign with our pooled results, and less than half reflect statistical significance. The results on the financial effects, regulatory effects, and two of the three physical effects are, however, in reasonably close accord with the results obtained under pooling. The conspicuous exception in this grouping is the plant age variable. On a year-by-year basis the coefficient varies here in sign and, more notably, in the only cases where a statistically significant effect is found it is positive. This contrasts sharply with the negative relationship obtained from estimating the pooled model. Finally, it is worth noting the disproportionately small amount of the variance in O\&M costs that the yearly model explains for the years 1988 and 1989 , in contrast to the other yearly equations.

${ }^{1}$ Maddala (1977, pp. 322-326). 
Table 6.2 Regression results of a yearly model

\begin{tabular}{|c|c|c|c|c|c|}
\hline Variable & $\begin{array}{c}\text { Equation } 1 \\
1986\end{array}$ & $\begin{array}{c}\text { Equation } 2 \\
1987\end{array}$ & $\begin{array}{c}\text { Equation } 3 \\
1988\end{array}$ & $\begin{array}{c}\text { Equation } 4 \\
1989\end{array}$ & $\begin{array}{c}\text { Equation } 5 \\
1990\end{array}$ \\
\hline Intercept & - & - & - & - & - \\
\hline \multicolumn{6}{|l|}{ Physical Effects: } \\
\hline AGE & $3.11 * *$ & 0.49 & -1.51 & -0.12 & $3.54 *$ \\
\hline OUTAGE & $0.014 * *$ & 0.003 & $0.032 *$ & 0.007 & $0.014 * *$ \\
\hline SIZEMW & $0.044 *$ & $0.10 *$ & $0.05 * *$ & $0.05 *$ & $0.042 *$ \\
\hline \multicolumn{6}{|l|}{ Regulatory Effects: } \\
\hline REP*FAC & $-0.053 * *$ & $-0.12 *$ & $0.09 * *$ & -0.012 & $-0.06 *$ \\
\hline REP*FAC*PUC & $0.021 *$ & $0.04 *$ & $-0.27 * *$ & -0.01 & $0.005 * *$ \\
\hline PENALTY & $0.23 *$ & 0.006 & $-0.55 *$ & $0.21 * *$ & -0.06 \\
\hline \multicolumn{6}{|l|}{ EIP Effects: } \\
\hline PGTYPE1 & -5.23 & -2.63 & 2.50 & 0.94 & $12.7 *$ \\
\hline PGTYPE3 & - & - & -10.8 & 17.4 & -5.64 \\
\hline PGTYPE2\$FSPRED & $-2.18 *$ & $-2.54 *$ & $-3.74 *$ & $2.57 *$ & $-2.41 *$ \\
\hline \multicolumn{6}{|l|}{ Financial Effects: } \\
\hline RPP & -0.026 & 0.061 & $0.28 *$ & -0.014 & $0.12 *$ \\
\hline FSPRED & $-37.7 *$ & 6.18 & 3.1 & $-34.6 * *$ & -13.4 \\
\hline Estimator & OLSQ & OLSQ & OLSQ & OLSQ & OLSQ \\
\hline Obs & 37 & 39 & 45 & 47 & 46 \\
\hline Adj- $R^{2}$ & 0.77 & 0.70 & 0.42 & 0.51 & 0.76 \\
\hline R M S E & 14.2 & 13.5 & 17.0 & 18.6 & 14.7 \\
\hline Coeff Var & 12.7 & 12.3 & 15.8 & 16.9 & 13.4 \\
\hline
\end{tabular}

* Statistically Significant at the 95 percent level

**. Statistically Significant at the 80 percent level 


\section{Inferences on EIPs and Financial Strength}

While the range of inferences from the estimation results contained in Section 6 can vary across a wide spectrum of impacts (physical to financial), this section is devoted strictly to a further interpretation and evaluation of the results relating to EIP impacts and the effects of financial status. The econometric results obtained from this initial investigation of industry operating data are far from clear cut and unequivocal. However mixed, it would nevertheless be useful and illustrative of our findings to date to explore their implications further. The estimates underlying this treatment are those of the pooled model under transformation for outlier error terms (Equation 5 of Table 6.1, based on Belsley et al. 1980). This model explains the highest proportion of observed variance in plant O\&M costs over the 1986-1990 period, and possesses the finest degree of "precision" about the estimated regression. For a general relationship to use for evaluation purposes, this may reflect the best steady-state implications that can be drawn from the data, subject to the significant caveat about the presence of parameter instability over the yearly models.

Figure 7.1 displays a very simple illustration of the comparative impact of the presence of general EIPs. Our results indicate that plants located in states with such EIPs generally spend about $\$ 2.3$ million per year more on O\&M than plants in states where EIPs have not be instituted. On average for the entire sample of all plants this effect amounts to roughly $\$ 0.5$ million for the $1986-1990$ sample period; a comparatively small amount, but a positive and statistically significant one, nevertheless. This partial effect is portrayed in Figure 7.1 by the two bars on the left-hand side of the chart ("EIP-1").

EIPs which grant rewards or assess penalties for plant performance standards based on bands for the plant capacity factor are another, partial impact of EIPs captured in our specification ("EIP-2"). Plants which operate under such incentive structures spend approximately $\$ 1.5 \mathrm{mil}-$ lion more on O\&M annually than those plants that do not. Industry-wide, this partial effect accounts for roughly $\$ 0.83$ million per year more in O\&M outlays.

These partial effects are melded into a composite or total impact in the far right-hand side of Figure 7.1. On average, EIPs appear to account for $\$ 1.32$ million per year more in plant O\&M spending. This is only slightly over 1 percent of average plant spending on non-fuel O\&M. Although, as our regression results indicate, an owner/operator financial status is inversely associated with O\&M overall (that is, stronger firms apparently tend to spend less on O\&M than weaker ones), the model also permits the examination of owner response to EIP as a function of how healthy they are financially. Since rewards/penalties under plant factor programs have been penalties, we've seen above that O\&M expenditures have been stimulated as a result. Our results indicate further that this effect is strengthened statistically by financial status. In other words, the weaker financially an owner/ operator is, the more they spent on O\&M under these EIPs. Since these influences manifest themselves through management/financial decision making and the industry's overall health via the cost of capital, this seems to reflect that weaker firms are more sensitive to adverse impacts stemming from unsatisfactory plant performance because their cost of capital may induce greater regulatory oversight. Stronger financial firms may not be as sensitive to performance-based EIPs because the rewards/penalties and their implications may not have as dramatic an effect on capital costs. The degree of impact by financial status is illustrated in Figure 7.2.

A negative coefficient on EIP rewards/penalties occurred in virtually all the estimated models from above. However, on average, penalties have dominated rewards, so that payments have been negative. Coupled with the negative slope coefficient on this variable, a positive impact results. A logical question arising from this finding is, if performance improved industry-wide to the point that payments were positive in the net, or they became reward payments, would plant $O \& M$ outlays be cut back? To the degree that O\&M is a factor in plant safety performance, this may be reason for concern by regulators. However, such an extrapolation would be outside our sample experience and not valid. The model would have to be re-estimated with updates on operating experience to make legitimate predictions such as this. 
EIPs and Financial Strength

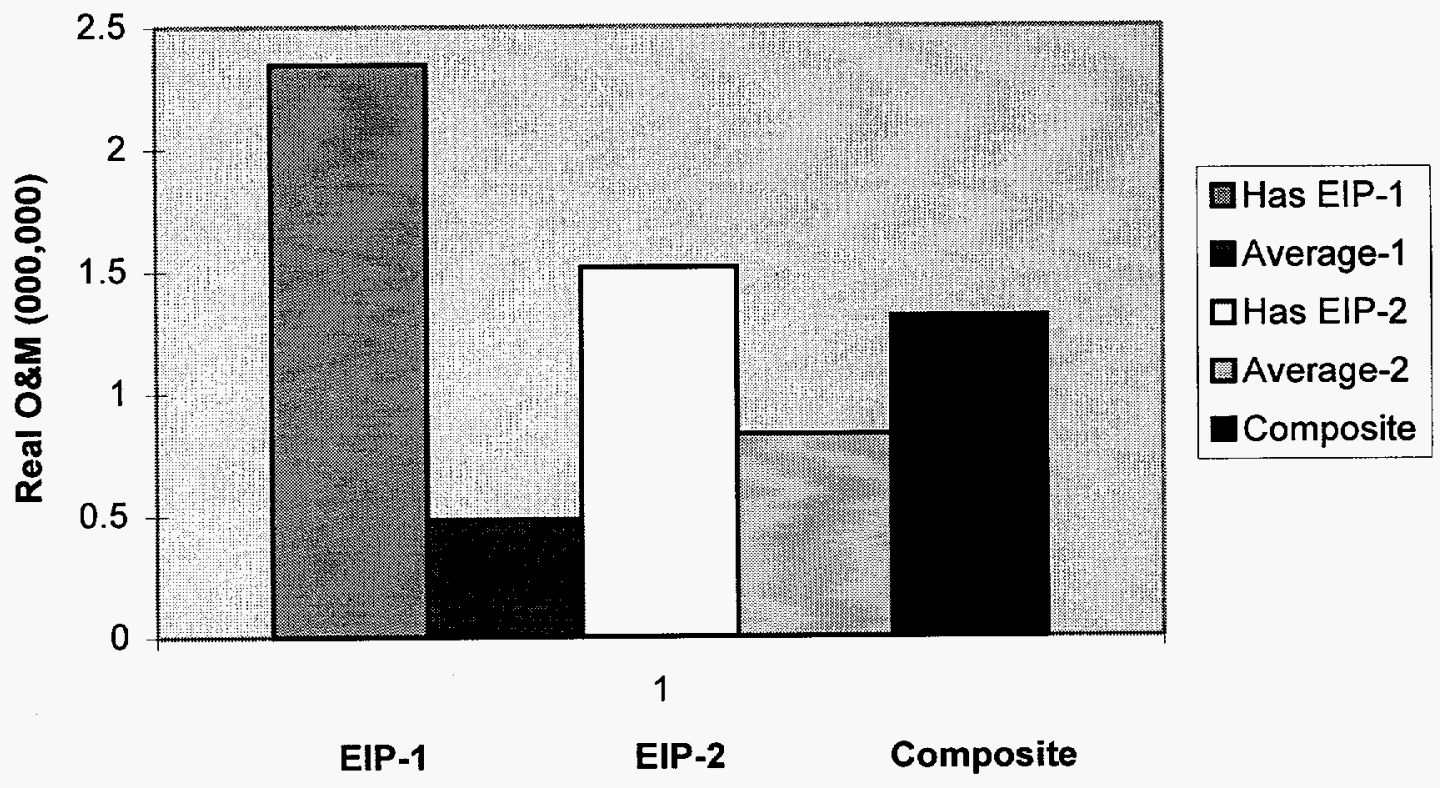

Figure 7.1 Partial and total EIP effects on O\&M

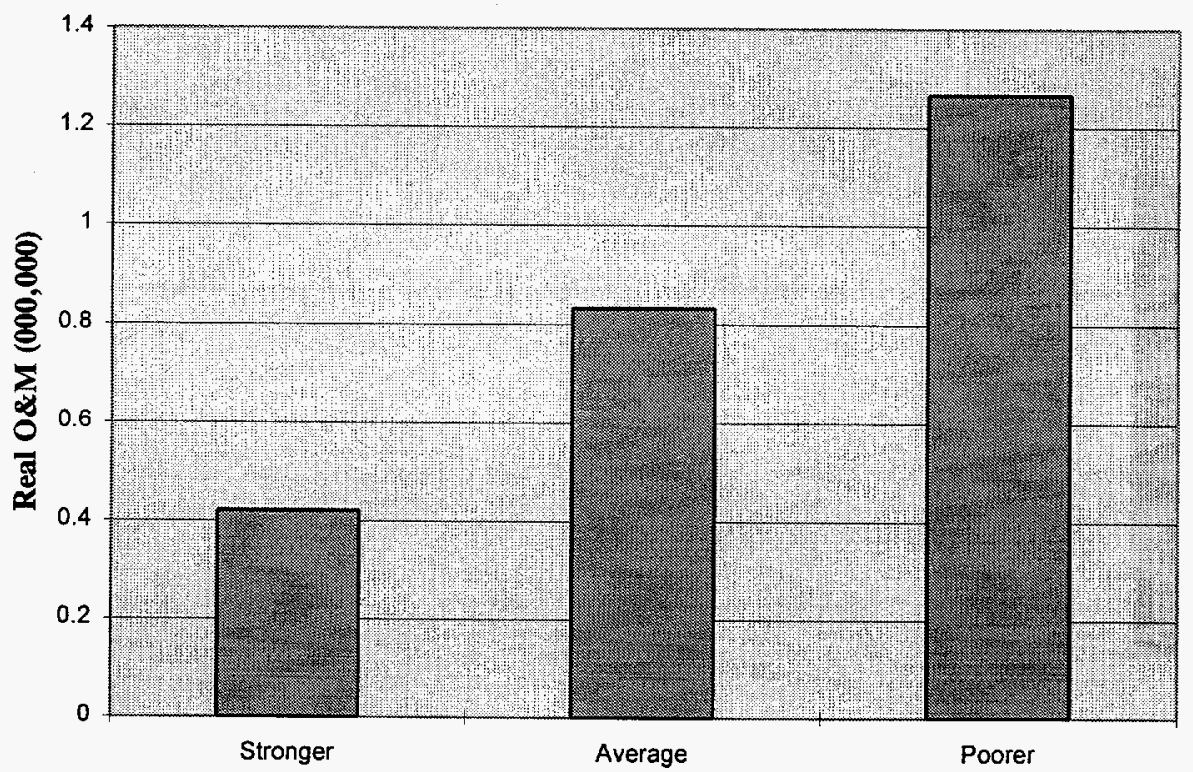

Financial Status

Figure 7.2 Financial status and EIP impacts on plant O\&M 


\section{Conclusions and Recommendations}

The conclusions from this analysis are relatively straightforward, but not entirely unequivocal. First, EIPs are a significant statistical factor in explaining the observed behavior of plant O\&M expenditures over time. However, an evaluation of the size of the effects indicates that they are comparatively small in relation to financial, regulatory, and physical effects.

The estimates of EIP effects can be susceptible to dramatic overstatement depending on the form of the model used in estimation. Considerable care needs to be exercised at this stage of a study to guard against seriously erroneous inferences that could influence policy making. The fixed effects model appears to produce the most reliable estimates in comparison to the other two candidate versions. Needless to say, extreme care must be taken in drawing inferences from a time series of cross-sectional data such as this.

Financial strength also appears to be a significant factor in plant owner/operator decisions relating to O\&M spending. This finding is very uniform across all the estimated models. Financially weaker firms spend proportionately more on O\&M than do stronger firms in our sample, all else equal. This effect also carries over to owner/operator response to rewards/penalties under EIPs; weaker firms appear to respond to EIP incentive payments somewhat more than stronger ones do.

Also noteworthy is the apparent, diminished impact of NRC-levied penalties for safety violations. In our preferred results, this effect is no longer a statistically significant one. This result suggests that the declining influence of this factor noted in the EIA (1991) study appears to have continued into the 1986-1990 period. However, our estimates for the impacts of plant aging and replacement power purchases seem to remain comparable with the earlier periods covered in the EIA analysis.

Another major, underlying objective of this research is largely of a methodological variety. Are statistical models of the variety here suitable and sufficiently informative for addressing policy issues, and are they a good enough substitute for more tedious case-study analyses? While more work would have to be devoted to this matter for any decisive conclusion to be reached, the results so far are very encouraging and much of them seem consistent with other research and are reasonable. However, the parameter instability issue raised and identified in Section 6.3 indicates continued analysis is necessary.

Along these lines, and in an attempt to better understand the yearly results and reconcile them with the findings from our pooled analysis, several important endeavors suggest themselves to complement and extend our current findings:

- The next link from O\&M expenditures and plant safety performance needs to be specified. An initial approach relying on the General Linear Statistical Model (Baker et al. 1995) indicates a somewhat positive or direct association between these variables. An approach put forth in Kavanaugh and Monroe (1995) looks especially promising in building upon that work.

- The informational content of the data sets assembled for this study is considerable. To exploit this and the knowledge achieved while implementing the analysis, it would be worthwhile to augment the data with updates and continued maintenance. This would support continued analysis of relationships like those examined in Sections 5 through 7, as well as new ones of concern to policy makers and regulators as they may arise.

- Our results underscore the extreme changes in coefficient estimates and their associated inferences for regulatory policy of nuclear power plants. The robustness of our initial findings should be tested with more generalized estimators of the fixed effects regression model.

- An analysis of the components of O\&M costs in a consistent, simultaneous model would move our specifications closer to the structural processes associated with O\&M functions. Further statistical analysis of this more refined examination could potentially enhance the credibility of the approach and the reasonableness of our inferences. 


\section{References}

Atkinson, S. E., and R. Halvorsen. 1990. "Tests of Allocative Efficiency in Regulated Multi-Product Firms." Resources and Energy 12:65-77.

Averch, H., and L. L. Johnson. 1962. "Behavior of the Firm under Regulatory Constraint." American Economic Review 52:1052-1069.

Baker, K. A. 1992. Support for the Evaluation of PUC Economic Incentive Programs. Task 4 Letter Report, Pacific Northwest Laboratory, Richland, Washington.

Baker, K. A., R. J. Schoenberg, and A. C. Bittner. 1995. An Examination of the Effects of Economics Incentive Programs on Nuclear Safety. Letter Report to the Pacific Northwest Laboratory under ILA-214968-A, Battelle Seattle Research Center, Seattle, Washington.

Belsley, D. A., A. E. Kuh, and R. E. Welsch. 1980. Regression Diagnostics. J. Wiley and Sons, New York.

Cowing, T. G., and R. Stevenson. 1982. "Automatic Adjustment Clauses and Allocative Efficiency in Public Utilities." Journal of Economics and Business 34:317-329.

Edelman, R. 1991. NRC Screening Program. Report under contract to the U.S. Nuclear Regulatory Commission, Washington, D.C.

Energy Information Administration (EIA). 1988. An Analysis of Nuclear Power Plant Operating Costs. DOE/EIA-0511, Energy Information Administration, Washington, D.C.

Energy Information Administration (EIA). 1991. An Analysis of Nuclear Power Plant Operating Costs. DOE/EIA-0547, Energy Information Administration, Washington, D.C.

Farber, S. 1991. "Nuclear Power, Systematic Risk, and the Cost of Capital." Contemporary Policy Issues 9:73-82.

Gollop, F. M., and S. Karlson. 1978. "The Impact of the Fuel Adjustment Mechanism on Economic Efficiency." The Review of Economics and Statistics 60:574-584.

Joskow, P. L., and G. A. Rozanski. 1979. "The Effects of Learning By Doing on Nuclear Plant Operating Reliability." The Review of Economics and Statistics 61:61-168.

Judge, G. C., W. E. Griffiths, R. C. Hill, and T-C. Lee. 1980. The Theory and Practice of Econometrics. J. Wiley and Sons, New York.

Kavanaugh, D. C., and W. B. Ashton. 1995. The Specification and Estimation of Technological Change in Electricity Production. PNL-10383, Pacific Northwest National Laboratory, Richland, Washington.

Kavanaugh, D. C., K. A. Baker, R. J. Schoenberg, G. S. Haber, and W. H. Monroe. 1993. Measures of Financial Status and Nuclear Power Plant Safety Performance. Task 2 Letter Report to the Nuclear Regulatory Commission, Pacific Northwest National Laboratory, Richland, Washington. 
Kavanaugh, D. C., and W. H. Monroe. 1995. Alternative Approaches to Modeling Impacts on Commercial Nuclear Power Plant Safety Performance. Letter Report to the Nuclear Regulatory Commission, Pacific Northwest National Laboratory, Richland, Washington.

Kavanaugh, D. C., and R. Wood . 1994. Economic Incentive Programs and Nuclear Power Plant Performance. PNL-SA-24538, Pacific Northwest National Laboratory, Richland, Washington. Presented at the Industry Studies on Energy and Resources Session at the 69th Annual WEA International Conference, Vancouver, British Columbia, July 1, 1994.

Komanoff, C. 1981. Power Plant Cost Escalation: Nuclear and Coal Costs, Regulation and Economics. Komanoff Energy Associates, New York.

Krautmann, A. C., and J. L. Solow. 1988. "Economies of Scale in Nuclear Power Generation." Southern Economics Journal 55:70-85.

Krautmann, A. C., and J. L. Solow. 1992. "Nuclear Power Plant Performance: The Post Three Mile Island Era." Energy Economics 14:209-216.

Maddala, G. S. 1977. Econometrics. McGraw-Hill, New York.

Martin, R. L., P. Hendrickson, and J. Olson. 1989. Incentive Regulation of Nuclear Power Plant by State Public Utility Commissions. NUREG/CR-5509, U.S. Nuclear Regulatory Commission, Washington, D.C.

Martin, R. L., K. A. Baker, and J. Olson. 1991. Incentive Regulation of Nuclear Power Plants by State Regulators. NUREG/CR-4911, U.S. Nuclear Regulatory Commission, Washington, D.C.

McKinney, M. D., and D. B. Elliot. 1993. Incentive Regulation of Investor-Owned Nuclear Power Plants by Public Utility Regulators. NUREG/CR-5975, U.S. Nuclear Regulatory Commission, Washington, D.C.

McKinney, M. D., H. Seeley, C. Merritt, and D. Baker. 1995. Incentive Regulation of Investor-Owned Nuclear Power Plants by Public Utility Regulators. NUREG/CR-5975, Rev. 1, U.S. Nuclear Regulatory Commission, Washington, D.C.

Moody's Investor Services, Inc. 1980-1991. Moody's Utility Manual. Moody's Investor Services, Inc., New York.

Nuclear Regulatory Commission (NRC). 1991. An Evaluation of Nuclear Power Plant Operating and Maintenance Costs. Management Report to the Office of Nuclear Reactor Regulation, Rockville, Maryland.

Rothwell, G. 1990. "Utilization and Service: Decomposing Nuclear Reactor Capacity Factors." Resources and Energy 12:215-229. 


\section{Appendix A}

Discussion of Data and Sources 


\section{Appendix A}

\section{Discussion of Data and Sources}

\section{A.1 Variable Measures and Data}

The data assembled for the O\&M expenditure model was drawn from a number of sources. The primary sources include the following:

- Utility Data Institute, Power Plant Operations, 1981-1991

- Utility Data Institute, Company Data File, 1981-1991

- Utility Data Institute, Nuclear Power Plant File, 1981-1991

- Replacement Power Purchase Costs, 1984-1990

- National Regulatory Research Institute (NRRI) surveys on fuel adjustment cost mechanisms

- Moody's Bond Ratings for Electrics, 1982-1990

- Argus Research's PUC/Public Service Commission (PSC) Ratings, 1985-1991

- Handy-Whitman industry cost data

- Selected gross domestic product deflators and other indices for labor costs.

A list of the specific, investor-owned utility plants is contained in Appendix C.

O\&M Annual Expenditures (O\&M): This information was obtained from the Utility Data Institute (UDI) data bases. Annual spending for O\&M is taken as the sum from a number of components. The information was obtained from Federal Energy Regulatory Commission (FERC) Form 1, EIA Form 412, and/or Rural Electriciation Administration (REA) Form 12G. A small amount of information in the UDI files is obtained directly from utility accounting departments.

Listed below are 13 categories used as components of O\&M. The first 8 refer to operation expenses while the last 5 indicate maintenance expenses.

(1) coolant and water expenses

(2) steam expenses

(3) cost of steam from other sources

(4) steam transfer credit

(5) operation supervision and engineering

(6) miscellaneous nuclear power expenses 
Appendix A

(7) electric expenses

(8) rental expenses

(9) maintenance supervision and engineering

(10) maintenance structures expenses

(11) maintenance of boiler plant

(12) maintenance of electric plant

(13) maintenance of miscellaneous nuclear plant.

The expenses for each of these components were summed to obtain total unadjusted O\&M expenses for the reporting year. Both nominal and deflated values were maintained for analysis. The real O\&M values are in terms of 1990 dollars.

Age of Plant (AGE): This information was obtained from the UDI data base. The age of the nuclear plant(s) at the site during a given operating year is determined by computing the number of years since each plant first came on line. This is the difference between the current year of observation and the first year the plant comes on line.

Plant Capacity (SIZEMW): The nuclear capacity of the plant was measured by the gross nameplate capacity (MW) as reported in the FERC Form 1. This information was obtained from the UDI data files.

NRC Penalties during year (PENALTY): The penalty information was obtained from the UDI data base using the PENALTY-data file. Historical penalties are represented by the average annual penalty during the previous years. This is computed as the arithmetic mean of annual penalties in the previous years of operation.

Forced Outages (AVEOUT): The outage information was obtained from the UDI data base using the OUTAGE/YR-data file. Historical forced outages are represented by the average annual duration of forced outage (hours) for all years of operation before the current year. The average was computed using an arithmetic mean of the outages for years spanning up to the current year of observation.

PUC Rating (PUC): State regulatory climate in terms of the degree of favorability to the company's equity investors was obtained from the Argus Research Corporation (1993). The report provides ordinal representations of the regulatory climate for all states from 1986 through 1993.

Cost Index Variables: The cost index variables include labor, fuel, structure, production, and materials. Sources used for the index variables are (1) the Statistical Abstract of the United States (DOC 1991, 1992), and 2) the Handy Whitman Guide (1992). The file includes all information pertaining to cost indexes for labor, fuel, structure, production, and materials.

Fuel Adjustment Clause (FAC): Information concerning the existence of an FAC for each state and year was obtained from the National Association of Regulatory Utility Commissioners (NARUC) Annual Reports for 1985 through 1989 and 1991. Tables are provided in each report which identify each state and whether an FAC is in effect. Data was provided for 1990 from the NRRI (1991).

Economic Incentive Programs (EIP): Information regarding the penalties and rewards from EIPs was extracted form a series of reports by the Pacific Northwest National Laboratory (Martin et al. 1989, 1991) and McKinney and Elliot (1993).

EIA Data: The EIA did an earlier study which analyzed the similar data for an earlier period (EIA 1988, 1991). Some of the data used in the EIA study was provided in an appendix of the report and used as benchmarks for our measures. This information included the following: 
- Total O\&M expenditures during the year

- Total Capital Additions during the year

- Age of plants at the site

- Total NRC penalties during the year

- Indicator if FAC was in force in state of operation

- Total net capacity (MW) for all plants at the site.

Predicted Financial Strength (FSPRED): The financial strength of each utility was estimated using a linear model developed during this project; see Appendix B for an abridged discussion of earlier work by Kavanaugh et al. (1993).

Cost of Replacement Power (RPP): The average daily cost of replacement power was computed for each year and site. This information was taken from VanKuiken et al. (1991).

Table A.1 shows the descriptive statistics on variables.

Table A.1 Descriptive statistics on variables

\begin{tabular}{lcc}
\hline \multicolumn{1}{c}{ Variable } & Mean & Std Dev. \\
\hline O \& M (millions/yr) & 110.67 & 59.81 \\
AGE & 11.32 & 6.51 \\
AVEOUT (hours/yr) & 1162 & 1013 \\
SIZEMW & 1511 & 802 \\
PENALTY (millions) & 0.0583 & 0.067 \\
PUC & 2.36 & NA* \\
RPP (millions/day) & 0.723 & 0.488 \\
PGTYPE1 & 0.206 & $\mathrm{NA}$ \\
PGTYPE2 & 0.55 & $\mathrm{NA}$ \\
PGTYPE3 & 0.014 & $\mathrm{NA}$ \\
PGTYPE2\$ (millions) & 0.207 & 1.87 \\
FSPRED & 1.97 & 0.39 \\
\hline
\end{tabular}

*NA $=$ not applicable. 
Appendix A

\section{A.2 Sources and References}

Argus Research Corporation. 1993. Argus Utility Scope. Argus Research Corporation, New York.

Energy Information Administration (EIA). 1988. An Analysis of Nuclear Power Plant Operating Costs. DOE/EIA-0511, Energy Information Administration, Washington, D.C.

Energy Information Administration (EIA0. 1991. An Analysis of Nuclear Power Plant Operating Costs. DOE/EIA-0547, Energy Information Administration, Washington, D.C.

Handy-Whitman Guide. 1992. Utility Construction Cost Indices. Whitman-Reguardt and Associates, Baltimore, Maryland.

Kavanaugh, D. C., K. A. Baker, R. J. Schoenberg, G. S. Haber, and W. H. Monroe. 1993. Measures of Financial Status and Nuclear Power Plant Safety Performance. Task 2 Letter Report to the Nuclear Regulatory Commission, Pacific Northwest National Laboratory, Richland, Washington.

Martin, R. L., P. Hendrickson, and J. Olson. 1989. Incentive Regulation of Nuclear Power Plant by State Public Utility Commissions. NUREG/CR-5509, U.S. Nuclear Regulatory Commission, Washington, D.C.

Martin, R. L., K. A. Baker, and J. Olson. 1991. Incentive Regulation of Nuclear Power Plants by State Regulators. NUREG/CR-4911, U.S. Nuclear Regulatory Commission, Washington, D.C.

McKinney, M. D., D. B. Elliot. (1993). Incentive Regulation of Investor-Owned Nuclear Power Plants by Public Utility Regulators. NUREG/CR-5975, U.S. Nuclear Regulatory Commission, Washington, D.C.

National Association of Regulatory Utility Commissioners (NARUC). 1985-1990. Annual Report. National Association of Regulatory Utility Commissioners, Washington, D.C.

National Regulatory Research Institute (NRRI). 1991. Current FAC and PGA Practices: Implications for Ratemaking in Competitive Markets, Volume II: Survey Responses. NRRI-91-13, National Regulatory Research Institute, Columbus, Ohio.

Vankuiken, J. C., K. A. Guziel, D. L. Williams, and W. A. Buehring. 1991. Replacement Energy Costs for Nuclear Electricity-Generating Units in the United States. NUREG/CR-4012, Prepared for the Nuclear Regulatory Commission, Argonne National Laboratory, Chicago, Illinois.

U.S. Department of Commerce (DOC). 1991. Statistical Abstract of the United States, 1990. U.S. Department of Commerce, Washington, D.C.

U.S. Department of Commerce (DOC). 1992. Statistical Abstract of the United States, 1991. U.S. Department of Commerce, Washington, D.C. 
Appendix B

Measuring Utility Company Financial Status 


\section{Appendix B}

\section{Measuring Utility Company Financial Status}

The purpose of this appendix is to provide a stand-alone discussion of the development and results from intermediate analyses that necessarily preceded the direct examination of the impacts of EIPs and financial strength on O\&M expenditures. This is a condensed discussion of the treatment and empirical analysis contained in Kavanaugh et al. (1993).

The financial status of nuclear plant owners/operators plays a direct role in a number of the empirical thrusts of the project: First, to what degree does financial status account for observed variation in plant safety performance? Second, are company outlays on fixed O\&M expenditure items partially influenced by the utility's financial health? Third, how is a company's financial status affected by state promulgated rules governing plant performance enhancements? The first and third of these are dealt with by Baker et al. (1995). The second is covered by the research encompassed in this report.

An earlier study conducted by Edelman (1991) for the NRC was a statistical inquiry on electric utility financial conditions. The Edelman study used two multivariate statistical approaches to establish a framework to predict a company's financial strength as a function of a set of traditional financial characteristics. The results were then used as the basis of a menudriven screening tool for predicting changes in financial strength as a function of changes in the financial characteristics. The empirical content of the Edelman screening model rests on sample data of 35 randomly selected utilities/holding company subsidiaries for the year 1989 . The first technique, multiple discriminate analysis (MDA), had a predictive capability of correctly classifying companies in their actual quality group of $100 \%$. The multiple regression model (conditioned solely on data for the variables indicated from the MDA results) had a somewhat lower successful classification rate of about 89 percent.

The interval selected as an outcome of Phase I to the work plan (Baker 1992) spans the period 1986 to 1990 . Essentially, this amounts to a five-year time frame with annual observations on approximately 50-60 companies which own/operate commercial nuclear power steam-generation plants. This is customarily referred to as a time series/cross section sample. While this type of sample information is desirable in terms of permitting the fullest latitude of controlling for inter-year as well as inter-firm effects associated with our formulations, it also creates more stringent data requisites than either pure time series or pure cross section models. Part of these are the availability of measures for financial status for each year of the 1986-1990 interval. The results available from the Edelman model are therefore insufficient for the purposes here. ${ }^{1}$

Another special feature of the financial status variable is its role in the model specifications as a explanatory variable and as a dependent variable. Given this jointly-determined attribute of a company's financial condition, an instrumental variable approach is called for, and this partly motivates the approach outlined below.

The path followed for this intermediate task of developing financial status measures uses the Edelman model as an initial basis. Guided by the financial characteristics variables specified in the Edelman regression model, observations for 60 utilities were gathered from electronic and hard copy sources on the following variables:

\footnotetext{
${ }^{1}$ An expeditious path of evaluating the Edelman 1989 model at different values for the regressor variable was one possibility, but this ignores the very likely possibility that the presumption of coefficient invariability is highly tenuous for even a short five-year span of time.
} 
Appendix B

- Moody's Bond Rating (RATING)

- Earnings Per Share Growth Rate (EPSGRO)

- Share of Equity Capital in Capitalization (EQUITY)

- Long-term Interest Coverage Ratio (COVERAGE)

- Current Liabilities to Total Revenues (LIBTOREV)

The ratings service selected was Moody's Bond Ratings (Moody's Investor Services, Inc. 1980-1991). Ratings fall into nine categories, ranging from Aaal (the highest possible rating) to $\mathrm{C} 3$ (the lowest possible rating). Following Edelman, bonds between Aaa (1) and Aa (1 through 3) are rated "HIGH," bonds between A (1 through 3 ) and $\mathrm{Ba}(1$ through 3$)$ are rated "MEDIUM," and bonds between B (1 through 3 ) and C (3) are rated "LOW." Moody's maintains $25 \%$ of issues in the "HIGH" and $25 \%$ of issues in the "LOW" category. As a consequence, changes in the rating of a given issue may reflect the introduction of new issues and their effect on the distribution of company ratings rather than any substantial change in objective quality.

Regression models of the same form as Edelman's were estimated for each year independently for the pooled sample and for the pooled sample with intercept shifts for inter-year effects (the "least squares dummy variable" specification of the General Linear Model). Given that the model specification was restricted to be the same as the Edelman model, no analysis of other variables, functional form, nor direct significance tests were performed.

\section{B.1 Sources and References}

Baker, K. 1992. Support for the Evaluation of PUC Economic Incentive Programs. Task 4 Letter Report to the Pacific Northwest National Laboratory, Battelle Seattle Research Center, Seattle, Washington.

Baker, K. A., R. J. Schoenberg, and A. C. Bittner. 1995. An Examination of the Effects of Economics Incentive Programs on Nuclear Safety. Letter Report to the Pacific Northwest National Laboratory under ILA-214968-A, Battelle Seattle Research Center, Seattle, Washington.

Edelman, R. 1991. NRC Screening Program. Report under contract to the Nuclear Regulatory Commission, Washington, D.C.

Kavanaugh, D. C., K. A. Baker, R. J. Schoenberg, G. S. Haber, and W. H. Monroe. 1993. Measures of Financial Status and Nuclear Power Plant Safety Performance. Task 2 Letter Report to the Nuclear Regulatory Commission, Pacific Northwest National Laboratory, Richland, Washington.

Moody's Investor Services, Inc. 1980-1991. Moody's Utility Manual. Moody's Investor Services, Inc., New York. 
Appendix C

Plant List 


\section{Appendix C}

\section{Plant List}

LISTING OF 47 SITES USED IN REGRESSIONS

$\begin{array}{llll}\text { ARK } & \text { ARKANSAS_ONE } & \text { NMP } & \text { NINE_MILE_POINT_1 } \\ \text { BRA } & \text { BRAIDWOOD } & \text { OCE } & \text { OCONEE } \\ \text { BRP } & \text { BIG_ROCK_POINT } & \text { PAL } & \text { PALISADES } \\ \text { BRU } & \text { BRUNSWICK } & \text { PAV } & \text { PALO_VERDE } \\ \text { BYR } & \text { BYRON } & \text { PEB } & \text { PEACH_BOTTOM } \\ \text { CAL } & \text { CALLAWAY } & \text { PER } & \text { PERRY_(OH) } \\ \text { CAT } & \text { CATAWBA } & \text { POB } & \text { POINT_BEACH } \\ \text { CRR } & \text { CRYSTAL_RIVER_3 } & \text { PRI } & \text { PRAIRIE_ISLAND } \\ \text { DAB } & \text { DAVIS_BESSE } & \text { QUC } & \text { QUAD_CITIES } \\ \text { DIC } & \text { DIABLO_CANYON } & \text { RIB } & \text { RIVER_BEND } \\ \text { DRE } & \text { DRESDEN } & \text { ROB } & \text { ROBINSON_2 } \\ \text { DUA } & \text { DUANE_ARNOLD } & \text { SAL } & \text { SALEM } \\ \text { FER } & \text { FERMI } & \text { SAO } & \text { SAN_ONOFRE } \\ \text { FSV } & \text { FORT_ST_VRAIN } & \text { STL } & \text { ST_LUCIE } \\ \text { GIN } & \text { GINNA } & \text { STX } & \text { SOUTH_TEXAS } \\ \text { HAR } & \text { HARRIS } & \text { SUM } & \text { SUMMER } \\ \text { HOC } & \text { HOPE_CREEK } & \text { SUR } & \text { SURRY } \\ \text { KEW } & \text { KEWAUNEE } & \text { SUS } & \text { SUSQUEHANNA } \\ \text { LAS } & \text { LASALLE } & \text { TRO } & \text { TROJAN } \\ \text { LIM } & \text { LIMERICK } & \text { TUP } & \text { TURKE_POINT_3\&4 } \\ \text { MCG } & \text { MCGUIRE } & \text { VMY } & \text { VERMONT_YANKEE } \\ \text { MON } & \text { MONTICELLO } & \text { WOC } & \text { WOLF_CREEK } \\ \text { MYA } & \text { MAINE_YANKEE } & \text { ZIO } & \text { ZION } \\ \text { NAN } & \text { NORTH_ANNA } & & \end{array}$




\section{Distribution}

No. of

Copies

\section{OFFSITE}

$50 \quad$ R. Wood (50)

Nuclear Reactor Regulation 0-11-D23

\section{ONSITE}

50 Pacific Northwest Laboratory

D. C. Kavanaugh (41)

P. Hendrickson
No. of

Copies

M. D. McKinney

Publishing Coordination

Technical Report Files (5)

1 Battelle Human Affairs Research Center

K. Baker

Distr.1 


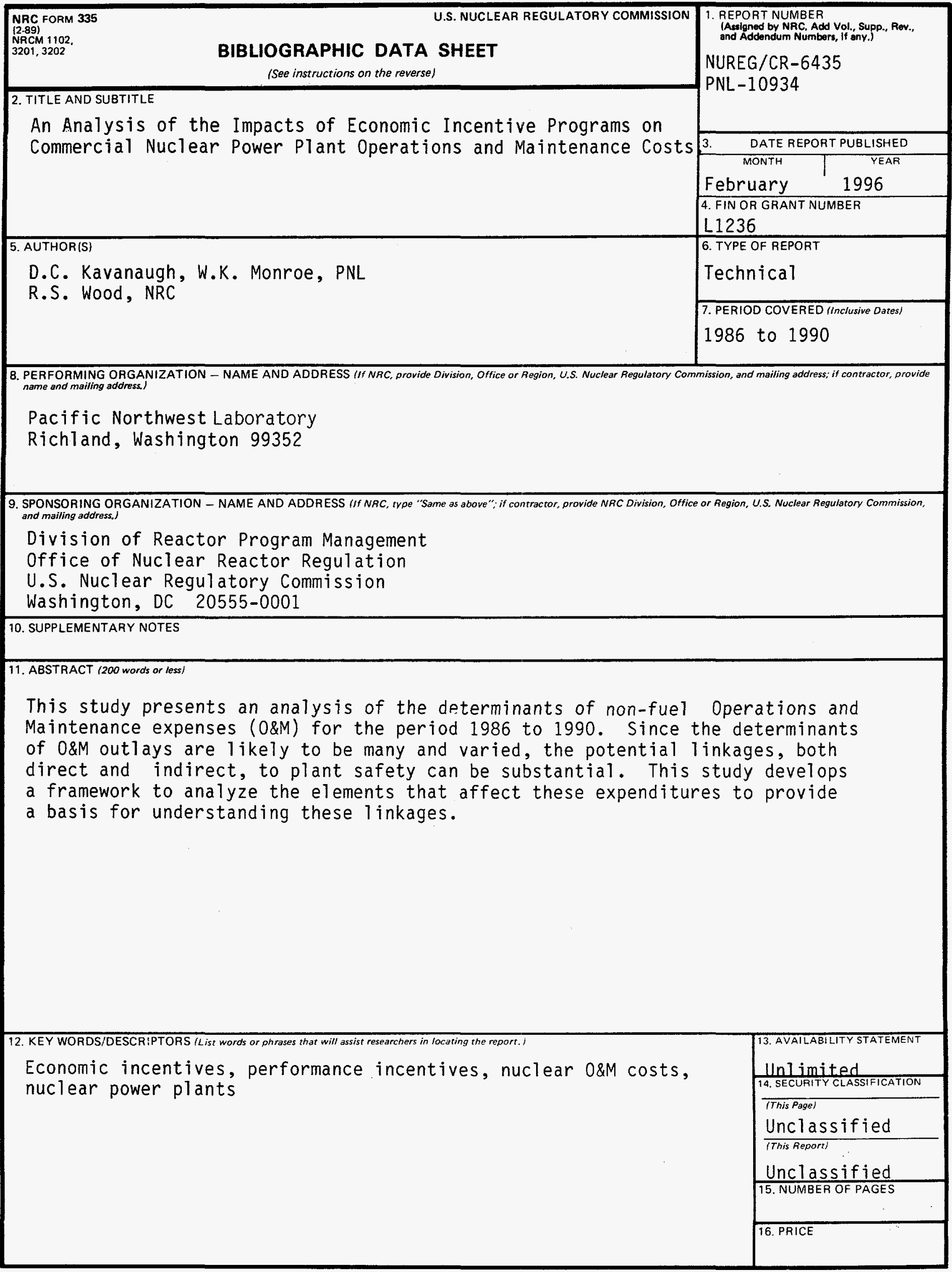

